\title{
Oct4 mediates Müller glia reprogramming and cell cycle exit during retina regeneration in zebrafish
}

\author{
Poonam Sharma, Shivangi Gupta*, Mansi Chaudhary*, Soumitra Mitra*, Bindia Chawla, Mohammad Anwar Khursheed, \\ Rajesh Ramachandran (1)
}

\begin{abstract}
Octamer-binding transcription factor 4 (Oct4, also known as Pou5F3) is an essential pluripotency-inducing factor, governing a plethora of biological functions during cellular reprogramming. Retina regeneration in zebrafish involves reprogramming of Müller glia (MG) into a proliferating population of progenitors (MGPCs) with stem cell-like characteristics, along with upregulation of pluripotency-inducing factors. However, the significance of Oct4 during retina regeneration remains elusive. In this study, we show an early panretinal induction of Oct4, which is essential for MG reprogramming through the regulation of several regeneration-associated factors such as Ascl1a, Lin28a, Sox2, Zeb, E-cadherin, and various miRNAs, namely, let-7a, miR-200a/miR$200 \mathrm{~b}$, and $\mathrm{miR}-143 / \mathrm{miR}-145$. We also show the crucial roles played by Oct4 during cell cycle exit of MGPCs in collaboration with members of nucleosome remodeling and deacetylase complex such as Hdac1. Notably, Oct4 regulates Tgf- $\beta$ signaling negatively during MG reprogramming, and positively to cause cycle exit of MGPCs. Our study reveals unique mechanistic involvement of Oct4, during MG reprogramming and cell cycle exit in zebrafish, which may also account for the inefficient retina regeneration in mammals.
\end{abstract}

DOI 10.26508/Isa.201900548 | Received 11 September 2019 | Revised 24 September 2019 | Accepted 24 September 2019 | Published online 8 October 2019

\section{Introduction}

Tissue regeneration is a complex phenomenon in which the damaged part of the organ is restored to normalcy through a series of genetic and epigenetic transformations of cells near the injury site. Regenerative capability is often limited in the nervous tissue of mammals, compared with their hair, skin, or liver. Interestingly, vertebrates such as fishes and frogs possess remarkable regenerative potential in almost all organs (Gemberling et al, 2013). One of the well-characterized model organisms, zebrafish, has been extensively used to unravel molecular mechanisms underlying tissue regeneration in general and retina in particular (Goldman, 2014) Upon injury, the Müller glia (MG) cells of the retina reprogram themselves to give rise to MG-derived progenitor cells (MGPCS), which are capable of differentiating into various retinal cell types and MG, as confirmed by lineage tracing (Bernardos et al, 2007; Ramachandran et al, 2010b, 2012a). In comparison with zebrafish, mammalian MG often fails to elicit an adequate regenerative response to restore vision. It is believed that the retina being part of the central nervous system has an inhibitory environment regarding the growth of new nervous tissue. This scenario makes it really interesting to explore how the zebrafish central nervous system is capable of regeneration after an acute injury. Several studies, characterizing various molecular events with special reference to transcription factors, cell signaling networks, epigenome modification, etc., have revealed the complex nature of zebrafish retina regeneration (Goldman, 2014; Gorsuch \& Hyde, 2014; Wan \& Goldman, 2016). Many of such regenerationassociated gene expression events were missing or inadequate in the injured mammalian retina, which may account for lack of complete retina regeneration in them (Wilken \& Reh, 2016). Moreover, artificial induction of some of these transcription factors such as Ascl1a has paved way for improved regenerative response in the injured retina of mice (Brzezinski et al, 2011; Jorstad et al, 2017). However, lack of adequate regenerative response in mammalian models necessitates a deeper investigation into the MG reprogramming of zebrafish retina, which would enable us to connect the missing links of the ever-enigmatic regeneration cascade.

Cellular reprogramming, leading to the induction of progenitors that are capable of regeneration because of their stem cell-like properties, is a wonderful alternative to fibroblast-mediated wound closure and scar formation. Zebrafish retina adopts a plethora of mechanisms that trigger an effective regenerative response (Goldman, 2014; Gorsuch \& Hyde, 2014; Wan \& Goldman, 2016). The advent of knowledge about the induction of pluripotency in fibroblasts, mediated through pluripotency-inducing factors (PIFs), prompted us to look closely into their molecular functions in context to zebrafish retina regeneration where almost all PIFs are expressed soon after an acute injury (Ramachandran et al, 2010a;

Indian Institute of Science Education and Research, Mohali, India

Correspondence: rajeshra@iisermohali.ac.in

*Shivangi Gupta, Mansi Chaudhary, and Soumitra Mitra contributed equally to this work. 
Gorsuch et al, 2017). Although many of them such as Lin28a (Ramachandran et al, 2010a), Sox2 (Gorsuch et al, 2017), and Mycb (Mitra et al, 2019) are characterized previously, the importance of Oct4 still remains undetermined. Oct4 is a homeodomaincontaining transcription factor essential for the formation and maintenance of pluripotent stem cells (Nichols et al, 1998). Oct4 is also known to carry out diverse biological functions in embryonic stem cells, cancer cells, and epithelial to mesenchymal transition (EMT) (Radzisheuskaya \& Silva, 2014). Oct4 also mediates transcriptional repression through nucleosome remodeling and deacetylase (NuRD) complex during differentiation (Hu \& Wade, 2012). Importantly, Oct4 down-regulates the components of Tgf- $\beta$ signaling to facilitate cellular reprogramming in different physiological conditions (Li et al, 2010; Radzisheuskaya \& Silva, 2014). It is also important to note that (i) efficient induction of pluripotency necessitates a very high level of Oct4 (Nagamatsu et al, 2012; Polo et $\mathrm{al}, 2012$ ) and (ii) its expression levels can switch the fate of embryonic stem cells (Radzisheuskaya et al, 2013).

In this study, we explored the significance of the panretinal induction of Oct4 soon after the injury and its interrelationship with Tgf- $\beta$ signaling and other gene expression events at different phases of retina regeneration. We found unique dual roles of Oct4 during MG reprogramming in zebrafish. Furthermore, we demonstrate the significance of the contrasting role of Oct4-mediated signaling events towards the later stages, which is necessary for the cell cycle exit of MGPCs that paves way for complete regenerative response in the zebrafish retina.

\section{Results}

\section{Oct4 is rapidly induced during zebrafish retina regeneration}

The significance of Oct4 is well known to induce pluripotency in human and mouse fibroblasts (Lowry et al, 2008; Li et al, 2010; Radzisheuskaya \& Silva, 2014; Chen et al, 2016). Oct4 is also considered a single factor capable of executing a multitude of functions during cellular reprogramming and mesenchymal to epithelial transition (MET) (Radzisheuskaya \& Silva, 2014). Its induction during zebrafish retina regeneration is documented with limited information about its regulation (Ramachandran et al, 2010a). Here, we injured zebrafish retina by focal stab using a $30 \mathrm{G}$ needle. The oct4 mRNA levels were analyzed after retinal injury by RT-PCR and qRT-PCR (Fig 1A), which showed a double peak in its expression pattern. The first one is at 16 hours posti-njury (hpi), and the second at 4 days post-injury (dpi). The Oct 4 levels also showed a similar trend in Western blot analysis of its protein isolated from total retinal extracts at various times post-injury (Fig 1B). Further analysis by mRNA in situ hybridization (ISH) revealed that oct4 mRNA is expressed negligibly in the uninjured retina followed by a panretinal induction at $16 \mathrm{hpi}$. Later on, the oct4 expression stayed restricted to the site of injury from 2 to $7 \mathrm{dpi}$ (Fig 1C).

A closer evaluation of the oct4-expressing cells at $4 \mathrm{dpi}$, a time when the progenitor cell proliferation is at its peak, revealed that the oct $4^{+}$cells stay just adjacent to the actively proliferating progenitor cells seen through a BrdU pulse labeling assay (Fig 1D).
Quantitative analysis of the $\mathrm{BrdU}^{+}$and oct $^{+}$cells revealed that $\sim 10 \%$ of the total BrdU ${ }^{+}$cells showed oct 4 expression and about $12 \%$ of oct $4^{+}$cells exhibited the presence of BrdU from the pulse labeling (Fig 1E). Similar results were obtained for Oct4 protein expression in $4 \mathrm{dpi}$ retina of 1016tuba1a:GFP transgenic retina wherein the MGPCs showed GFP expression (Fig 1F) (Fausett \& Goldman, 2006). These observations suggested the following possibilities: (i) oct4-expressing cells do not proliferate but can direct the neighboring cells to proliferate and (ii) oct4 expression is a post-proliferative phenomenon. To determine which is the real scenario at $4 \mathrm{dpi}$, retinal sections were used to perform oct4 mRNA ISH, followed by staining with proliferating cell nuclear antigen (PCNA) and BrdU. PCNA has a longer half-life and stays detectable beyond the cell cycle exit (Mandyam et al, 2007; Kimmel \& Meyer, 2010; BolognaMolina et al, 2013). Hence, PCNA could be used as a marker of postproliferative status as well. Interestingly, we found that almost all $\mathrm{PCNA}^{+}$cells had the oct 4 expression, suggesting the existence of the second possibility (Fig $1 \mathrm{G}$ and $\mathrm{H}$ ). These observations were further confirmed by BrdU pulse labeling along with oct4 mRNA ISH at 2, 4, and $8 \mathrm{dpi}$ (Fig S1A). The quantification revealed that the propensity of BrdU and oct4 co-labeling increased only towards the end of the proliferative phase at $8 \mathrm{dpi}$ when most of the $\mathrm{BrdU}^{+}$cells were exiting the cell cycle (Fig S1B).

We then decided to explore the expression pattern of oct4 through a cell sorting approach, for which we used 1016tuba1a:GFP transgenic retina. GFP-positive and GFP-negative cells were used to assess the levels of oct4 mRNA both qualitatively and quantitatively (Fig 11 and J). High levels of oct4 mRNA were seen in GFP cells, which are similar to the PCNA ${ }^{+}$ones (Fig S1C), along with negligible expression in the $\mathrm{GFP}^{-}$ones. These observations suggested that despite being secluded from actively proliferating MGPCs, the oct4 expression is an immediate and transient feature of post-proliferative cells at $4 \mathrm{dpi}$.

We further explored the regulatory factors that could influence the expression of oct4 soon after the injury. One of the potential candidates was ascl1a, an essential regeneration-associated gene (Ramachandran et al, 2010a, 2011), which also shows a panretinal early expression soon after injury in zebrafish retina (Ramachandran et al, 2011), similar to oct4. To address whether Ascl1a influences oct4 expression, we checked the levels of oct 4 in the asclia knockdown background. We found a significant decline in oct4 mRNA levels because of ascl1a knockdown (Fig S1D and E). Analysis of the oct4 promoter revealed several Ascl1a-binding sites (BSs), which were confirmed to be functional in a chromatin immunoprecipitation (ChIP) assay done using 16 hpi retinal extract (Fig S1F). These observations suggest that Ascl1a is one of the governing factors that cause the upregulation of Oct4.

\section{Oct4-mediated gene regulatory network is essential for retina regeneration}

We were intrigued by the fact that there is an abundant expression of oct4 mRNA panretinally at $16 \mathrm{hpi}$, which later on stayed restricted to post-proliferative MGPCs. To assess its significance, we adopted a knockdown approach to eliminate Oct4 soon after the injury using two different lissamine-tagged morpholino (MO)-based antisense oligos targeting oct4 mRNA. We performed the oct4 knockdown 
A

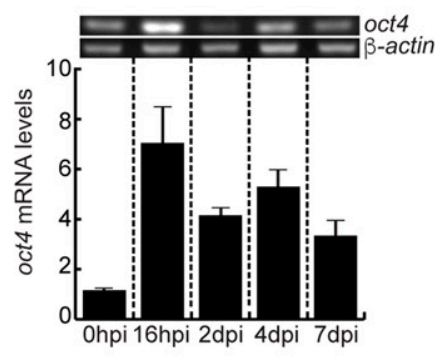

B

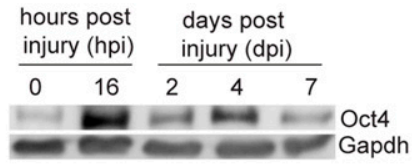

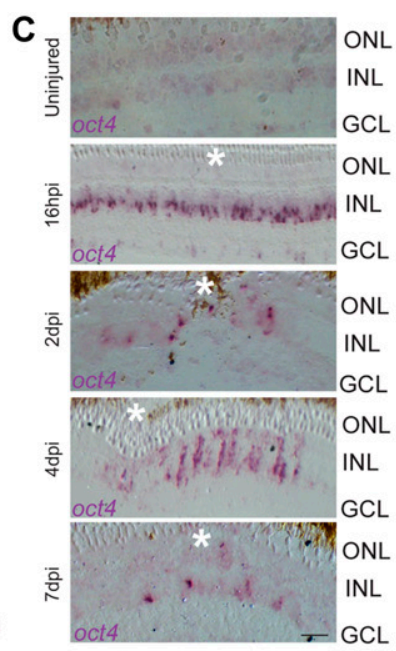

E

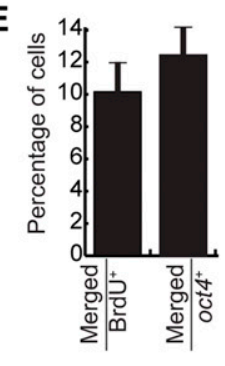

F

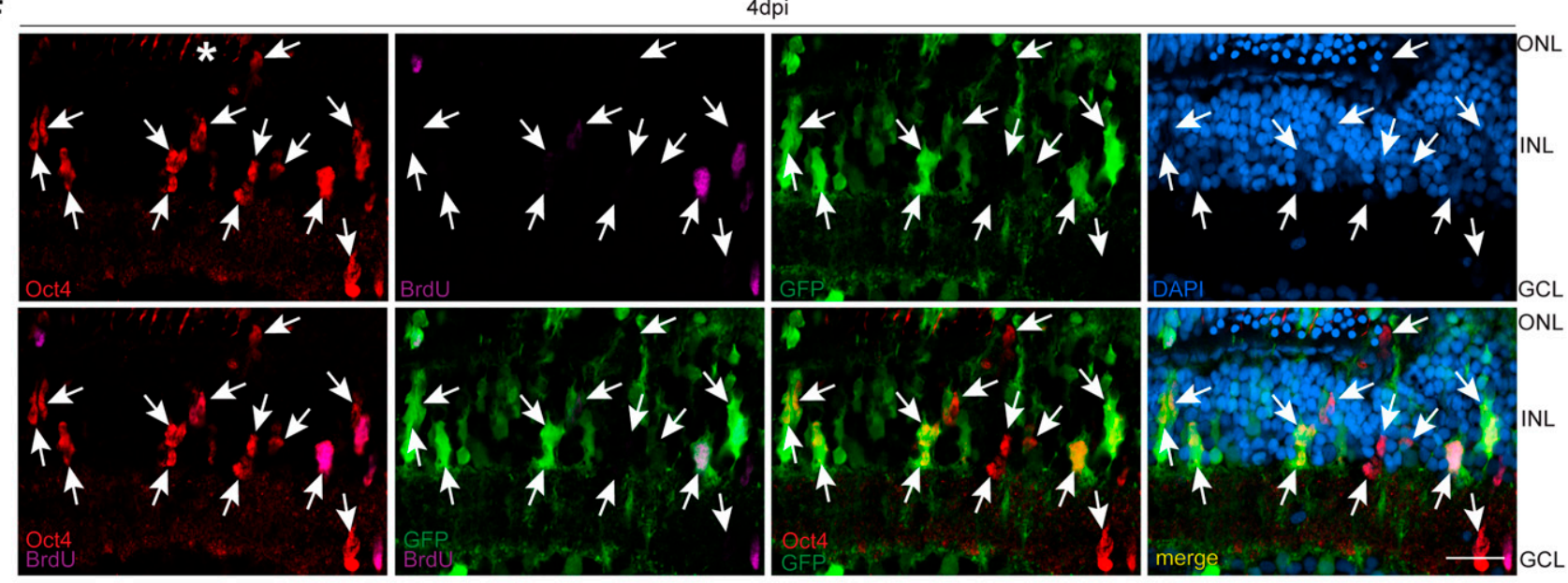

G

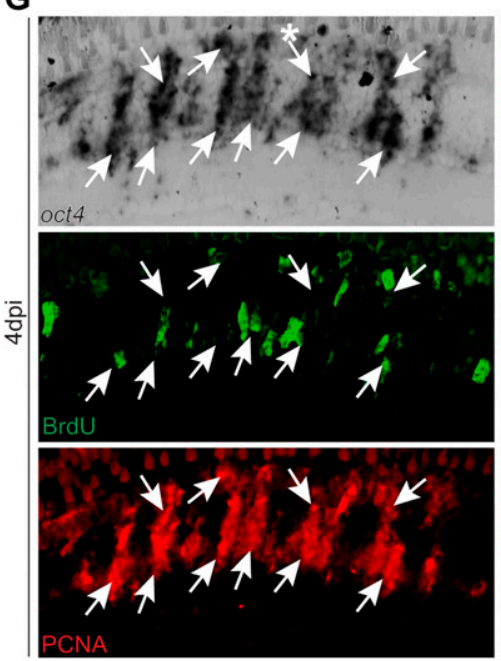

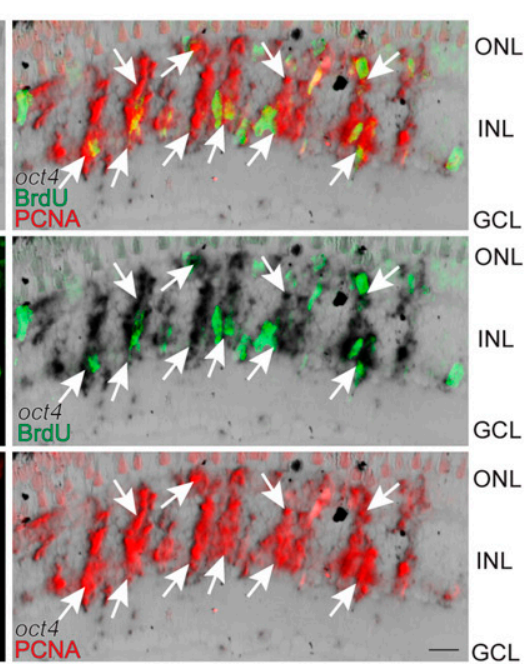

H

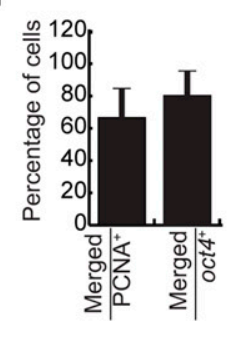

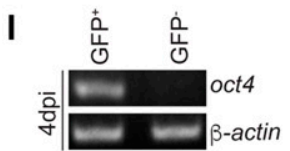

J

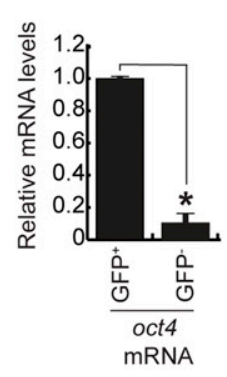

Figure 1. The expression pattern of Oct4, its association with MGPCs, and seclusion from BrdU ${ }^{+}$cells.

(A) RT PCR of oct4 mRNA (upper) and its qRT-PCR (lower) at various time points post retinal injury. (B) Western blot analysis of Oct4 from retinal extracts collected at different time points post injury. Gapdh is the loading control. (C) Bright-field (BF) microscopy images of retinal cross sections showing the mRNA ISH of oct4 at various time points post retinal injury. (D, E) BF and immunofluorescence (IF) confocal microscopy images of retinal cross section showing the mRNA ISH reveals the oct4 expression in the neighboring cells of BrdU ${ }^{+}$MGPCs at $4 \mathrm{dpi}$ (D), which is quantified (E). (D) White arrowheads mark BrdU ${ }^{+}$and oct $4^{-}$cells and white arrows mark oct $4^{+}$but $\mathrm{BrdU}^{-}$cells in (D). (F) IF confocal microscopy images of retinal cross section, which shows the Oct4 immunofluorescence in GFP ${ }^{+}$MGPCs in 4 dpi retina of 1016tuba1a:GFP 
experiments as per the experimental timeline (Fig 2A). As done with previous experiments, $3 \mathrm{~h}$ before harvesting, a BrdU/EdU pulse was given at $4 \mathrm{dpi}$ to assess the number of MGPCs in the oct 4 knockdown scenario. We found a significant decline in the number of $\mathrm{BrdU}^{+}$/ $\mathrm{EdU}^{+} \mathrm{MGPC}$ in an oct4 $\mathrm{MO}$ concentration-dependent manner in the retina at $4 \mathrm{dpi}$ (Figs $2 \mathrm{~B}$ and $\mathrm{C}$, and $\mathrm{S} 2 \mathrm{~A}$ and $\mathrm{B}$ ). The negative effect of oct4 knockdown on MGPC proliferation was rescued by the transfection of gfp-oct4 fusion mRNA into the retina at the time of injury (Fig S2C and D). Furthermore, the oct4 knockdown (Fig 2D) caused a decline in both oct4 mRNA and protein levels, which were confirmed by qRT-PCR (Fig 2E) and Western blot (Fig 2F) analysis of retinal lysates at both $16 \mathrm{hpi}$ and $2 \mathrm{dpi}$. The oct4 knockdown also caused a significant decline in regeneration-associated transcription factors Ascl1a (Ramachandran et al, 2010a, 2011) and Sox2 (Gorsuch et al, 2017) in $16 \mathrm{hpi}$ and $2 \mathrm{dpi}$ retina (Fig $2 \mathrm{E}$ and F). These observations supported the view that early induction of oct4 is necessary for the normal regenerative response of the retina.

We further explored the cis-regulatory regions of regenerationassociated genes ascl1a and oct4 itself for Oct4-binding consensus sequence ATGCAAAT (Kemler et al, 1991) (Oct4-BS). We found one Oct4-BS on the asclia promoter and five of them on oct4 promoter sequences. ChIP assay performed in $16 \mathrm{hpi} \mathrm{retinal} \mathrm{extract} \mathrm{confirmed}$ that Oct4 indeed bound to all the sites in oct4 and ascl1a gene promoter (Fig S3A and B). The mRNA ISHs of ascl1a and oct4 in oct4 knockdown background in $4 \mathrm{dpi}$ retina also supported the results above (Figs S3C, 2E, and F). The Oct4-mediated transactivation of ascl1a promoter is further confirmed by luciferase assay performed in zebrafish embryos co-injected with ascl1a promoter driving GFP-luciferase fusion construct along with oct4-targeting MO or oct4 mRNA (Fig S3D and E). These observations suggested that Oct4 and Ascl1a indulge in a mutual positive feedback loop during retina regeneration.

Interestingly, despite the reduction in the number of MGPCS upon oct4 knockdown, we saw an up-regulated expression of lin28a (Fig 2G-I), one of the PIFs essential for normal retina regeneration (Ramachandran et al, 2010a; Kaur et al, 2018). We sought to explore the reasons behind this intriguing finding. The analysis of the lin28a promoter did not show any Oct4-BS, which ruled out the possibility of Oct4 directly regulating lin28a. We then explored if the lin28a could be regulated through Her4.1, an effector of Delta-Notch signaling and transcriptional repressor of lin28a in regenerating retina (Mitra et al, 2018). We saw a significant decline in her4.1 levels in oct4 knockdown retina (Fig 2G-I), which explained the upregulated lin28a levels. Furthermore, analysis of her4.1 promoter revealed the presence of Oct4-BS, which was occupied by Oct4 as revealed from ChIP assay performed in 16 hpi retinal extract (Fig 2J). This finding affirms the indispensability of Oct4 in MGPC induction during retina regeneration.

Similarly, we explored whether the decline in $\mathrm{BrdU}^{+}$cells found in the retina because of the oct 4 knockdown affected the genes responsible for cell cycle progression. For this, we analyzed the expression pattern of several proliferation-associated genes such as cyclins and delta genes in oct4 knockdown background. The qRT-PCR analysis revealed that cyclin family members ccna1, ccnb1, ccnd1, and ccne1, and delta family dla, dlb, dlc, and dld indeed were down-regulated in agreement with reduced MGPC proliferation in the absence of Oct4 (Fig S3F). Taken together, these results revealed the potential roles played by Oct4 during MG reprogramming through regulation of ascl1a, sox2, her4.1, and lin28a to induce MGPCS.

\section{Oct4 regulates Tgf- $\beta$ signaling during retina regeneration}

Cellular reprogramming to induce pluripotent stem cells resembles MET in various aspects (Esteban et al, 2012; Shu \& Pei, 2014), which involves regulation of genes such as cdh1 (E-cadherin). One of the important functions governed by Oct4, while acting as a pluripotency inducer, is to activate $\mathrm{E}$-cadherin (Shen et al, 2014) and downregulate TGF- $\beta$ signaling ( $\mathrm{Li}$ et al, 2010). The Tgf- $\beta$ signaling is known to up-regulate the snail family of genes, which repress cellular reprogramming (Li et al, 2010). Snail also functions as a transcriptional repressor of E-cadherin in tumor cells (Batlle et al, 2000). We probed further if snail gene family members get upregulated because of Oct4 knockdown in regenerating retina. We found that four members of snail gene family, namely, snai1a, snai1b, snai2, and snai3 get significantly up-regulated in oct4 knockdown retina at $2 \mathrm{dpi}$ (Fig $3 \mathrm{~A}$ and $\mathrm{B}$ ). Supporting this observation, in contrast to the expression pattern of oct4 in 1016tuba1a: GFP transgenic retina (Fig 1J), we found down-regulation of snail gene family members in $\mathrm{GFP}^{+}$cells compared with rest of the retina (Fig S3G). Furthermore, the oct4 knockdown up-regulated the Tgf- $\beta$ signaling components such as tgfbr1b, tgfb2, and its effector genes tgfbi and smad7 in 2 dpi retina (Fig 3C). Subsequently, we explored if the oct4 knockdown influenced the expression of cdh1, which is important in imparting stemness properties to cells. We saw an increase in the levels of cdh1 in response to oct4 knockdown in 2 dpi retina (Fig 3D). In 1016tuba1a:GFP transgenic retina, we also saw a down-regulation of cdh1 in $\mathrm{GFP}^{+}$cells as compared with the rest of the retina (Fig S3H). In contrast to the previous reports (Redmer et al, 2011), wherein Oct4 activates cdh1, which can even replace the requirement of Oct4, we observed the opposite regulation in regenerating retina. Moreover, there was no Oct4-BS on the cdh1 promoter. Closer analysis of the cdh1 promoter sequences revealed the presence of BSs of Oct4-regulated transcription factors, namely, Ascl1a and Sox2. Interestingly, Ascl1a and Sox2 bound to their respective BSs, CACCTG (Ramachandran et al, 2010a) and CATTGTA (Mistri et al, 2015) on cdh1 promoter as revealed in a ChIP assay performed in $16 \mathrm{hpi}$ and 2 dpi retinal extracts (Fig 3E). However, the observed increase in cdh1 expression because of oct4 knockdown remained unclear. We speculate that some unknown repressors regulated by Oct4 could potentially mediate the regulation of cdh1. These

transgenic fish. White arrows mark Oct4 ${ }^{+}$and $\mathrm{GFP}^{+}$cells. DAPI was used as the counterstain to mark nucleus. (G, H) BF and IF confocal microscopy images of retinal cross section show the mRNA ISH of the oct4 in a significant proportion of PCNA ${ }^{+}$MGPCS at 4 dpi (G), which is quantified (H). (G) White arrows mark PCNA ${ }^{+}$cells that are oct4 $^{+}$in (G). (I, J) RT-PCR (I) and qRT-PCR (J) of oct4 mRNA from GFP ${ }^{+}$MGPCs compared with the GFP ${ }^{-}$cells present in rest of the retina from 1016tuba1a:GFP transgenic fish at 4 dpi, ${ }^{*} P<0.003$ ( $t$ test), $N=12$. Error bars are SD. (C, D, F, G) Scale bars, $10 \mu \mathrm{m}$; the asterisk marks the injury site; GCL, ganglion cell layer; INL, inner nuclear layer; $\mathrm{ONL}$, outer nuclear layer (C, D, F, G). 
A Injury+

$\mathrm{MO}+$

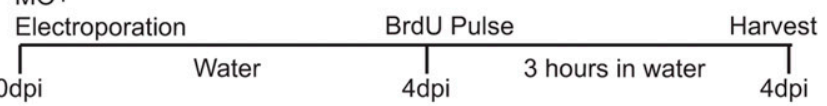

B

4dpi

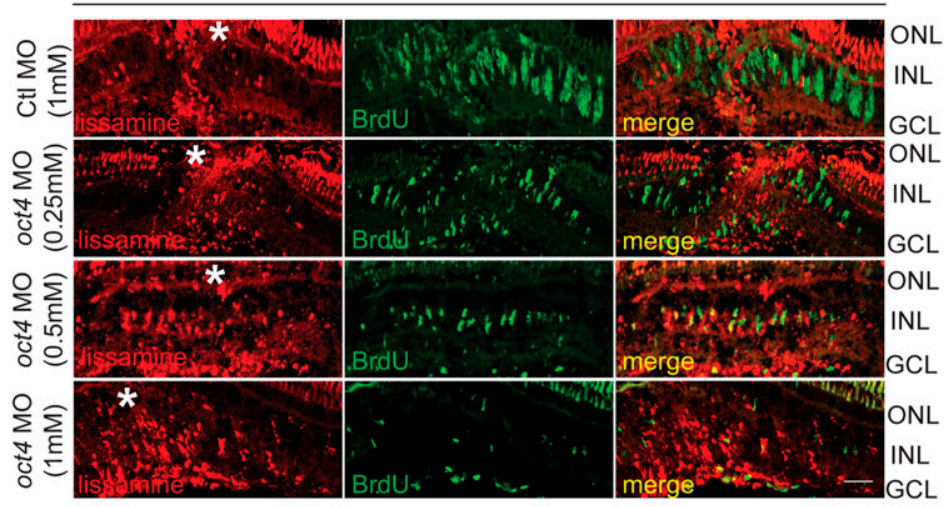

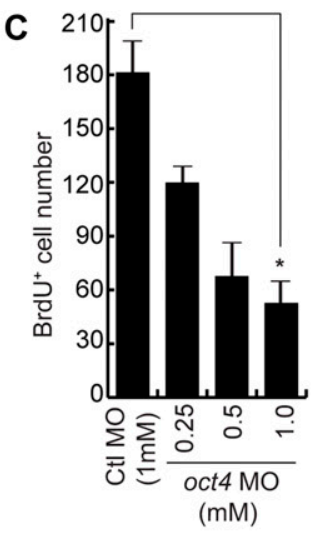

E

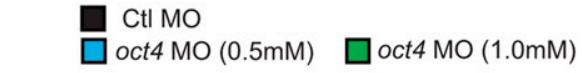

F
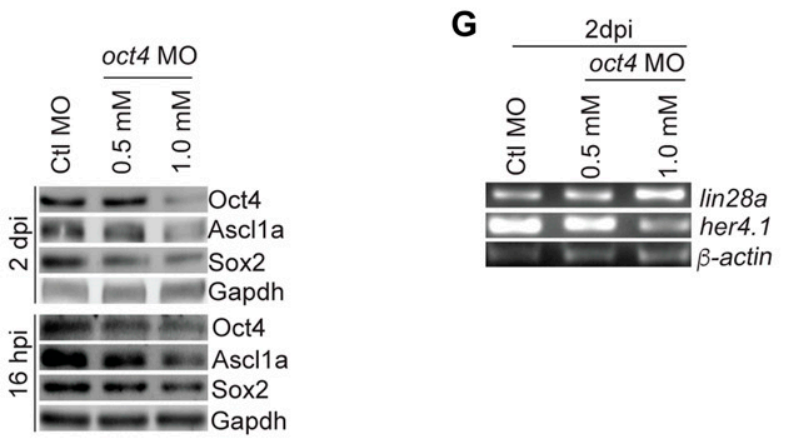

I

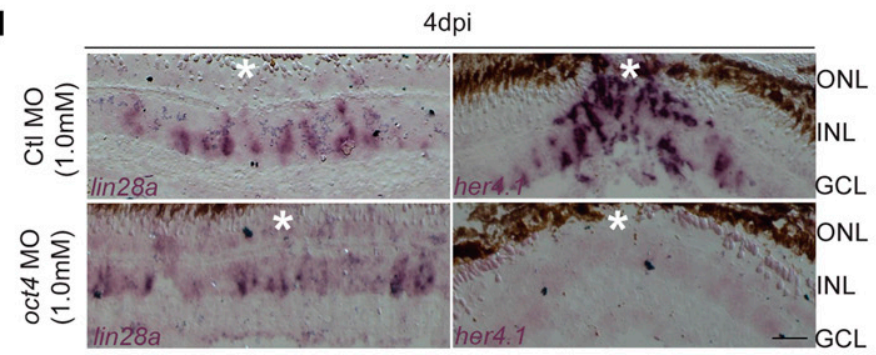

H

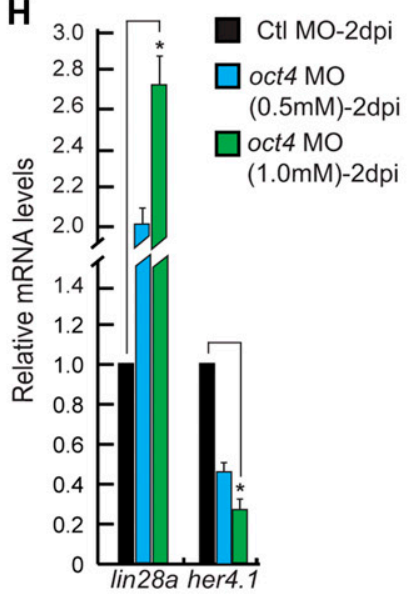

J

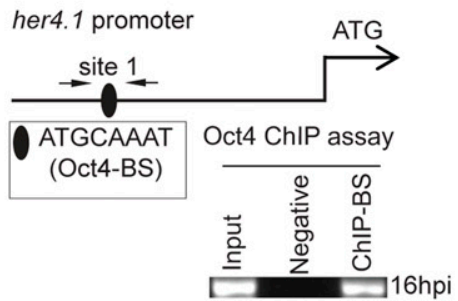

Figure 2. Oct4 is essential during retina regeneration.

(A) An experimental timeline that describes the MO delivery, electroporation, and BrdU pulse before harvesting at $4 \mathrm{dpi}$. (B, C) IF confocal microscopy images of retinal cross sections show the decline in BrdU ${ }^{+}$MGPCs with increasing concentrations of oct4 MO (lissamine tag) at $4 \mathrm{dpi}(\mathrm{B})$, which is quantified $(C)$; ${ }^{\star} P<0.0001$ ( $t$ test), $\mathrm{N}=4$. (D) An experimental timeline that describes the MO delivery, electroporation, and harvest at 16 hpi and 2 dpi. (E) The qRT-PCR analysis of oct4, ascl1a, and sox2 genes in oct4 knockdown retina at $2 \mathrm{dpi}$ and $16 \mathrm{hpi} ;{ }^{*} P<0.01$ ( $t$ test), $\mathrm{N}=4$. (F) Western blot analysis of Oct4, Ascl1a, and Sox2 from retinal extracts collected after oct4 knockdown at 16 hpi and 2 dpi. Gapdh is the loading control. (G, H) RT-PCR (G) and qRT-PCR (H) of lin28a and her4.1 in oct4 knockdown retina at 2 dpi. (I) BF microscopy images of 
results are suggestive of the existence of a functional Oct4/Ascl1a/ Sox2/E-cadherin and Oct4/Tgf- $\beta$ signaling/Snail regulatory axes necessary for the formation of MGPCS during retina regeneration.

\section{Oct4 influences miR-200/Zeb regulatory loop during regeneration}

Tissue reprogramming during regenerative response often involves a fine balance among various transcription factors and oscillations between EMT and MET (Liu et al, 2013; Forte et al, 2017). The initial phase of induced pluripotency in fibroblasts is similar to MET (Li et al, 2010). The zinc finger E-box-binding homeodomain transcriptionrepressing factors, ZEB1 and ZEB2, are necessary for normal development in vertebrates (Gheldof et al, 2012). ZEB1 also mediates EMT, the opposite phenomenon of MET, through transcriptional repression of E-cadherin (Chua et al, 2007; Peinado et al, 2007; SanchezTillo et al, 2010; Schulte et al, 2012; Galvan et al, 2015; Zhang et al, 2015) and members of miR-200 family (Wellner et al, 2009). To decipher whether similar pathways exist during retina regeneration, we explored the changes in the levels of zeb genes in response to retinal injury and oct4 knockdown. The zeb1a and zeb2a expression pattern in postinjured retina revealed an immediate early induction (Fig S3I), suggestive of their significance in early MG reprogramming during retina regeneration. With oct4 knockdown, the levels of zeb1a, zeb1b, zeb2a, and zeb2b were significantly down-regulated in a concentration-dependent manner in 2 dpi retina (Fig $3 \mathrm{~A}$ and $\mathrm{F}$ ). Further analysis of the zeb gene promoters revealed the existence of typical Oct4-BSs, which were occupied by the endogenous Oct4 as confirmed by ChIP assay performed using 16 hpi retinal extract (Fig 3G). Interestingly, analysis of mRNA levels of zeb gene family members revealed an elevated expression levels in $\mathrm{GFP}^{-}$cells than the GFP ${ }^{+}$ones sorted from 1016tuba1a:GFP transgenic retina (Fig S3J). Based on these observations, we speculated if the Zeb transcriptional repressors could be responsible for Oct4-mediated $c d h 1$ repression (Fig 3D) and inhibition of oct4 itself. To examine this, we transfected varying concentrations of zeb1a and zeb2a mRNA in postinjured retina and explored the levels of cdh1 and oct4. We found zeb1a (Fig $3 \mathrm{H}$ ) and zeb2a (Fig S3K) mRNA dose-dependent decline in the levels of both cdh1 and oct4 in $16 \mathrm{hpi}$ and $2 \mathrm{dpi}$ retina. These results suggest that Oct4-mediated regulation of cdh1 could be mediated through Zeb1a/Zeb2a, and considering the restricted expression pattern of oct4 in the $4 \mathrm{dpi}$ retina, we presume that Zeb1a/Zeb1b transcriptional repressors play a role in restricting the early panretinal expression of oct4 to the site of injury through a mutual regulatory relationship.

Next, we explored if the miR-200/Zeb1 axis contributed to the Oct4-mediated MG reprogramming. Zeb1 plays a transcriptional repressive role on $\mathrm{miR}$-200 promoter during zebrafish development (Vannier et al, 2013). To ascertain this, we checked the levels of miR$200 a$ and miR-200b, the translational repressors of zeb mRNAs (Park et al, 2008), in response to injury as well as oct4 knockdown in $2 \mathrm{dpi}$ retina. We found an up-regulation of miR-200a and miR-200b soon after injury (Fig S3L), and surprisingly further high levels of miR-200a and miR-200b in 2 dpi retina after oct4 knockdown (Fig 3I).
Similar to miR-200 family, both miR-143 and miR-145 had an immediate early up-regulation soon after retinal injury (Fig S3M) and high levels in oct4 knockdown retina (Fig 3I). The miR-143/miR-145 are inhibitors of stem cell characteristics and are also the translational repressors of PIFs such as oct4, cmyc, and klf4 mRNAs (Huang et al, 2012). In support of these observations, expression analysis of these miRNA genes revealed higher dose of expression in GFP-negative than observed in GFP-positive cells sorted from 1016tuba1a:GFP transgenic retina (Fig S3N). These results suggested the existence of a potential repressive mechanism on these miRNA promoters mediated through Oct4 in the retina. ChIP assay performed in 16 hpi retinal extract using anti-Oct4 antibody confirmed the binding of Oct4 on the promoters of miR-200a/ miR-200b (Fig 3J) and $\mathrm{miR}-143 / \mathrm{miR}-145$ (Fig 3K). We speculated that the repressive role of Oct4 binding on miR-200a/miR-200b and miR-143/miR-145 may be carried out in collaboration with repressive factors such as histone deacetylase1 (Hdac1), as reported in embryonic stem cells (van den Berg et al, 2010). The retinal ChIP assay performed using anti-Hdac1 antibody confirmed that it could bind to the Oct4-BS of both miR-200a/miR-200b and miR-143/miR-145 promoters (Fig 3) and $\mathrm{K}$ ). To validate these observations, we performed a coimmunoprecipitation (Co-IP) assay in 16 hpi retinal extracts using both anti-Oct4 and anti-Hdac1 antibodies in separate experiments and probed for both these proteins. Interestingly, we found Oct4-Hdac1 interactions as revealed by the Co-IP assay (Fig $3 \mathrm{~L}$ and $\mathrm{M}$ ). These results suggest that the Oct4 causes transcriptional activation of zeb mRNAs and repression of miR-200a/miR$200 \mathrm{~b}$ and $\mathrm{miR}-143 / \mathrm{miR}-145$.

\section{Snails, Zebs, miR200a/miR-200b/miR-143/miR-145, and Cdh1 regulates the number of MGPCs during regeneration}

Our study demonstrated the importance of Oct4 in regulating various factors such as Snails, Zebs, $\mathrm{miR200a/miR-200b/miR-143/}$ miR-145, and E-cadherin which are known to contribute to cellular reprogramming. However, the importance of these factors during retina regeneration remained obscure. To explore this, we decided to adopt a gene overexpression/knockdown approach in a contextdependent manner and also along with oct4 MO when required. As we demonstrated a decline in MGPC proliferation with oct4 knockdown (Fig 2B and C), along with an up-regulation of snail gene family members (Fig $3 \mathrm{~A}$ and B), we speculated that Snails might have important roles to play during retina regeneration. To address this question, we transfected the injured retina using snai1a, snai1b, snai2, and snai3 mRNAs in separate experiments. Interestingly, we found a significant decline in the number of MGPCs in retina transfected with snail gene family members in a concentrationdependent manner (Fig 4A and B). These results suggest the antiproliferative effect of Snails during MGPCS proliferation.

Similarly, we found a decline in the expression levels of zeb gene family members (Fig $3 \mathrm{~A}$ and F) because of oct4 knockdown. To ascertain if the oct4 knockdown-mediated decline in MGPCs could be

retinal cross sections show the expression of lin28a and her4.1 mRNA in oct4 knockdown retina at 4 dpi. (J) The her4.1 promoter schematic reveals the typical Oct4-BS (upper) and the retinal ChIP assay confirms the physical binding of Oct4 at the typical BS (lower) in 16 hpi retina. Ctl MO is control MO. Error bars are SD. (B, I) Scale bars, $10 \mu \mathrm{m}$; the asterisk marks the injury site; GCL, ganglion cell layer; INL, inner nuclear layer; ONL, outer nuclear layer (B, I). 
A

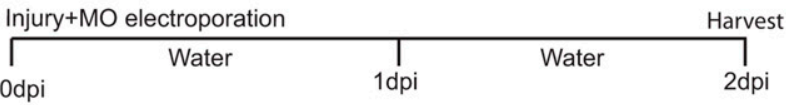

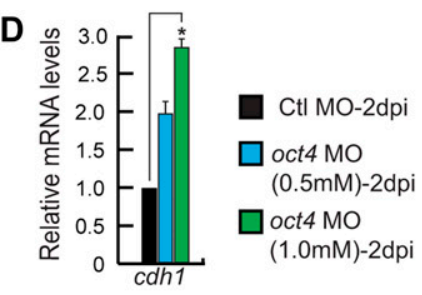

B

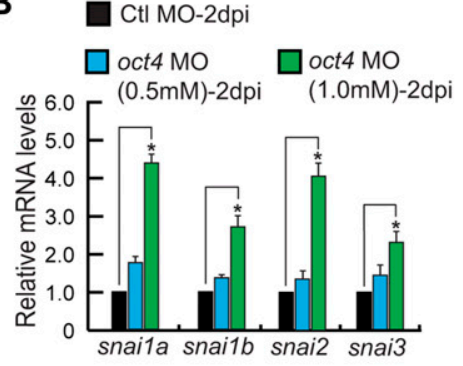

$\mathbf{F}$

Ctl MO-2dpi

$\square$ oct4 MO $(0.5 \mathrm{mM})-2 \mathrm{dpi} \quad(1.0 \mathrm{mM})-2 \mathrm{dpi}$

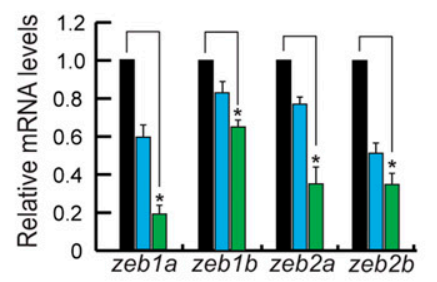

C $\square$ Ctl MO-2dpi $\square$ oct4 MO
$\square$ oct4 MO

$(1.0 \mathrm{mM})-2 \mathrm{dpi}$
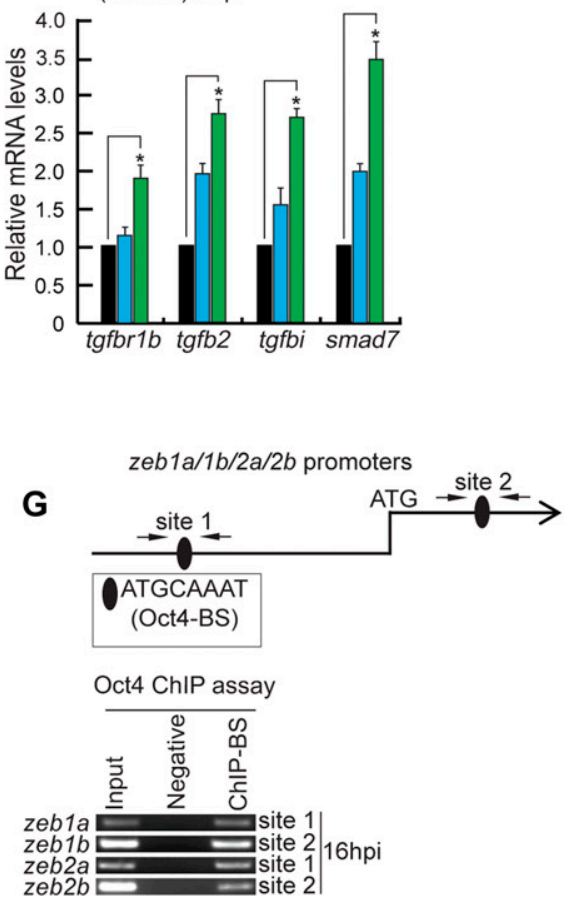

E

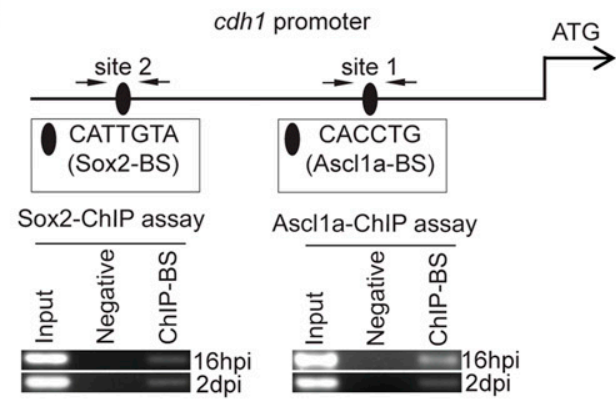

I

Ctl MO-2dpi $\square$ oct4 MO

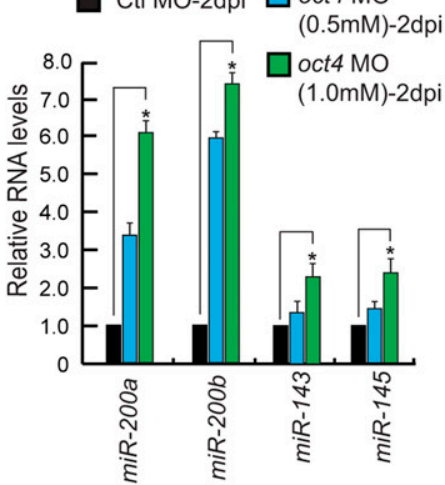

J miR-200a/miR-200b common promoter
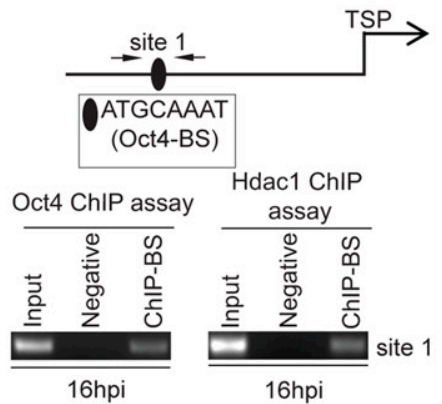

K $m i R-143 / m i R-145$ promoter

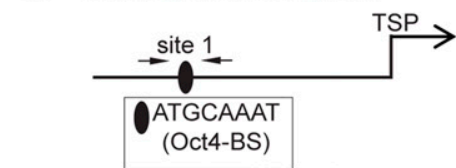

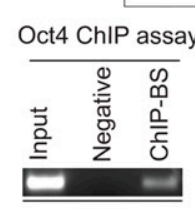

16hpi
H

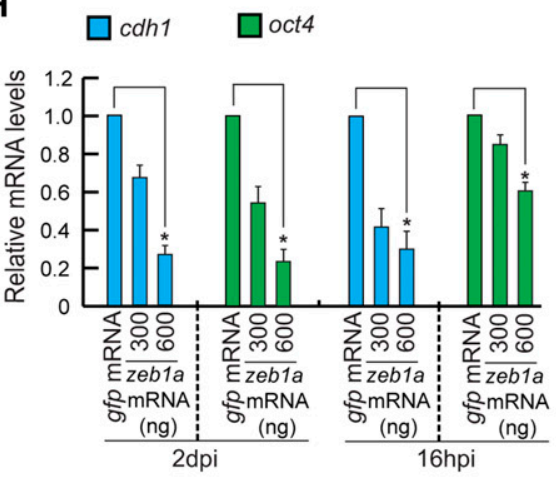

Figure 3. The importance of Oct4 during retina regeneration revealed through various gene regulatory events.

(A) An experimental timeline that describes the MO delivery, electroporation, and retina harvest at $2 \mathrm{dpi}$. (B) The qRT-PCR analysis of snail family genes in oct4 knockdown retina at $2 \mathrm{dpi} ;{ }^{*} P<0.004$ ( $t$ test), $N=4$. (C) qRT-PCR analysis of various component genes of Tgf- $\beta$ signaling in oct4 knockdown retina at 2 dpi; ${ }^{*} P<0.003$ ( $t$ test), $N=4$. (D) qRT-PCR analysis of $c d h 1$ mRNA in oct4 MO-electroporated retina at $2 \mathrm{dpi}$; ${ }^{*}<<0.01$ ( $t$ test), $N=4$. (E) The cdh1 promoter schematic reveals the Sox2 and Ascl1a BSs (upper), and the retinal ChIP assays confirm the physical binding of Sox 2 and Ascl1a (lower) in 16 hpi and 2 dpi retina. (F) qRT-PCR analysis of zeb family genes in oct4 knockdown retina at $2 \mathrm{dpi} ;{ }^{*} P<0.02$ ( $t$ test), $\mathrm{N}=4$. (G) The promoter and first intron schematic (upper) of zeb family genes reveal the presence of 
alleviated by Zeb overexpression, we adopted an experimental strategy in which gfp mRNA and zeb1a/zeb2a mRNA were transfected along with control or oct4 MO in separate experiments. These experiments were aimed at finding the influence of replenishment of Zeb in oct 4 knockdown retina and also the effect of Zeb overexpression in control MO-electroporated conditions. Interestingly, at $4 \mathrm{dpi}$, we found that overexpression of zeb1a (Fig 4C and D) and zeb2a (Fig S4A and B) had an anti-proliferative effect on MGPCs irrespective of whether control or oct4 MO were electroporated in the injured retina. It is also important to note in this context that Oct4 is expressed in GFP' MGPCS (Fig 1J) and the zeb gene family is expressed at higher levels in non-proliferating GFP $^{-}$cells (Fig S3J) of 1016tuba1a:gfp transgenic retina. These results suggest that Oct4 activates the zeb gene family to keep the proliferation within the desired limits.

Furthermore, we explored the significance of Oct4-mediated regulation of miR-200a, miR-200b, miR-143, and miR-145 genes during retina regeneration. We already demonstrated that Oct4 has a suppressive role on the expression of these miRNAs (Fig $3 \mathrm{I}-\mathrm{K})$ and an associated decline in MGPC proliferation. Furthermore, these four miRNAs showed a drastic up-regulation soon after a retinal injury (Fig S3L and $M$ ). In this scenario, we decided to knockdown these four miRNAs individually and probe for its influence on MGPC proliferation. Interestingly, knockdown of miR$200 a$ and miR-200b caused a profound increase in MGPCS (Fig 4E and $\mathrm{F}$ ), whereas the opposite was seen with $m i R-143$ and $m i R-145$ knockdown (Fig 4G and $\mathrm{H}$ ). These observations suggest the significant roles played by Oct4 in causing a definitive number of MGPCS at the site of injury, through the regulation of these miRNAs.

We then explored the significance of cdh1 up-regulation in the oct4 knockdown background (Fig 3D). For this, we targeted cdh1 mRNAs using MOs against it in control MO or oct4 MO-electroporated background. Interestingly, knockdown of cdh1 caused a robust decline in MGPCS proliferation in a dose-dependent manner both in control and oct4 MO-electroporated conditions (Fig 41 and J). The double knockdown of cdh1 and oct 4 had a more dramatic decrease in MGPC number (Fig $4 \mathrm{I}$ and J), suggesting that these two genes may also have an independent influence on total MGPC number in regenerating retina. Based on these results, we could assume that Oct4 influences retinal MGPC number through snail, zeb family members, miR-200al miR-200b/miR143/miR-145, and cdh1.

\section{Effects of Oct4 in vivo overexpression on gene regulation and cell proliferation}

We next decided to see the influence of Oct4 overexpression in the zebrafish retina. For this, the gfp-oct4 mRNA was transfected into the injured retina and was compared with gfp mRNA-transfected control for the regenerative response. We followed an experimental timeline up to $2 \mathrm{dpi} / 4 \mathrm{dpi}$ post oct4 transfection (Fig 5A). Interestingly, the overexpression of Oct4 caused a decline in $\mathrm{BrdU}^{+}$ cells in the 4 dpi retina (Fig $5 B$ and C). These results made us speculate that Oct4 if overexpressed, had a negative influence on cell proliferation. We then decided to use a range of oct4 mRNA concentrations such as $150,350,750$, and 1,000 ng to transfect into the injured retina. To our surprise, we found that there is an increase in cell proliferation in 150 and $350 \mathrm{ng}$ that decreased thereafter in 750 and 1,000 ng (Figs 5D and E, and S6A). Furthermore, on closer evaluation, it is seen that the Oct $4^{+}$cells, after oct4 mRNA transfection, were always present adjacent to the little number of BrdU ${ }^{+}$cells (Fig 5D). At lower concentrations, Oct4 had a pro-proliferative effect, whereas at higher concentrations, it had an anti-proliferative effect. This probably could be because of differential partner selection by Oct4 at various concentrations in the injured retina. We speculated a differential affinity collaboration of Oct 4 with transcriptional repressors such as histone deacetylase1 (Hdac1) during retina regeneration. Earlier studies have demonstrated the dependence of retina regeneration on differential regulation of Hdac1 in zebrafish (Mitra et al, 2018) and mice (Jorstad et al, 2017). To decipher if the differential collaboration of Oct4-Hdac1 existed, we decided to do a Co-IP of Oct4-Hdac1 complex using antibodies targeting both these proteins at various times postretinal injury. Interestingly, we found that Oct4 had less affinity to Hdac1 at early time points of retinal injury, which progressively enhanced towards the end of regeneration (Fig 5F). Based on these observations, we predicted that the differential effect of Oct4 overexpression on cell proliferation could also be under the influence of varying affinity to its collaborators such as Hdac1, which, as a transcriptional repressor, plays important roles during zebrafish retina regeneration. We then analyzed if the Hdac1 levels influenced the collaborative affinity of Oct 4 at the early stages of retina regeneration. For this, we transfected injured retina with hdac1 mRNA along with control gfp mRNA at 15 hpi. Interestingly, in gfp mRNA-transfected retina, we saw a similar affinity of Oct4 for Hdac1 (Fig 5G), while the overexpression of hdac1 abolished the existing affinity at 15 hpi (Fig 5F and G). In addition, we also explored if the loss of Oct4-Hdac1 collaboration in Hdac1-overexpressed conditions caused an effect on the number of MGPCs in regenerating retina. Overexpression of $\mathrm{Hdac1}$ significantly increased the number of MGPCS at $2 \mathrm{dpi}$ (Fig S4C and D), suggesting that the Oct4-Hdac1 collaboration is necessary to keep the number of MGPCs within the desired limits at the site of injury.

Gene expression analysis in oct4-overexpressed retina showed that the levels of zeb1a/zeb2a, miR-200a/miR-200b, and miR-143/ miR-145 family genes were opposite to what we found in oct4 knockdown background (Fig S4E and F). As discussed earlier, we

Oct4-BS, which is confirmed to be functional in a ChIP assay (lower) in the retina at $16 \mathrm{hpi}$. (H) qRT-PCR analysis of cdh1 and oct4 mRNA levels in the zeb1a-transfected retina at $2 \mathrm{dpi}$ and $16 \mathrm{hpi}$, compared with gfp control. (I) The qRT-PCR analysis of miR-200a, miR-200b, miR-143, and miR-145 genes in oct4 knockdown retina at $2 \mathrm{dpi} ;{ }^{*} P<0.02$ ( $t$ test), $\mathrm{N}=4$. (J, K) The promoter schematics of miR-200 family (gene cluster) (J, upper) and miR-143/miR-145 (gene cluster) (K, upper) reveal the presence of Oct4-BSs, which are confirmed to be functional using antibodies against Oct4 (lower left), and Hdac1 (lower right) in a ChIP assay, at 16 hpi. (L, M) Western blot analysis of Co-IP of Hdac1 and Oct4 in retinal extracts at $16 \mathrm{hpi} \mathrm{probed} \mathrm{with} \mathrm{anti-Hdac1} \mathrm{(L)} \mathrm{and} \mathrm{anti-Oct4} \mathrm{(M)} \mathrm{antibodies.} \mathrm{Ctl} \mathrm{MO} \mathrm{is} \mathrm{control} \mathrm{MO.}$ Error bars are SD. 
A

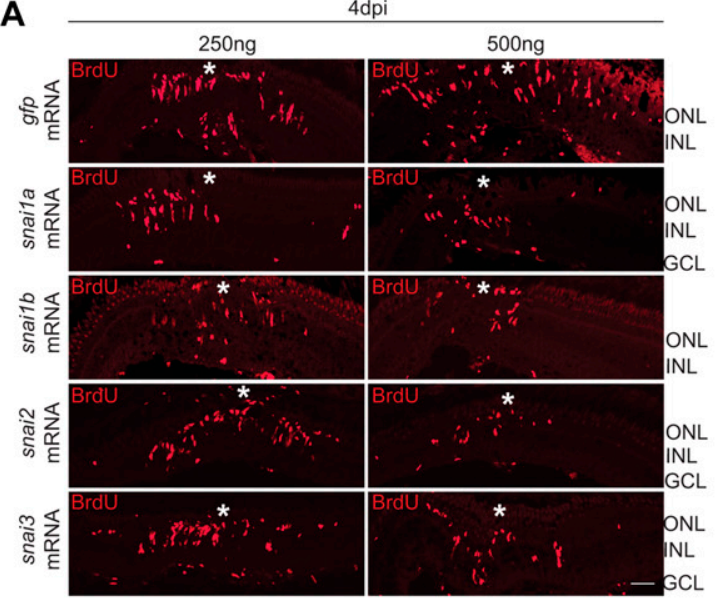

B

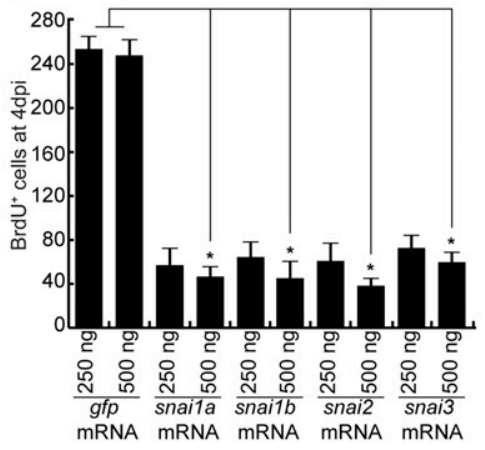

D

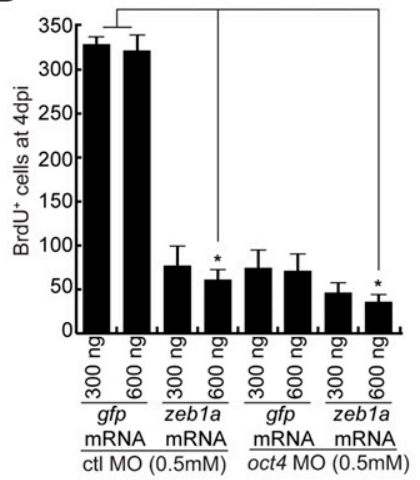

C

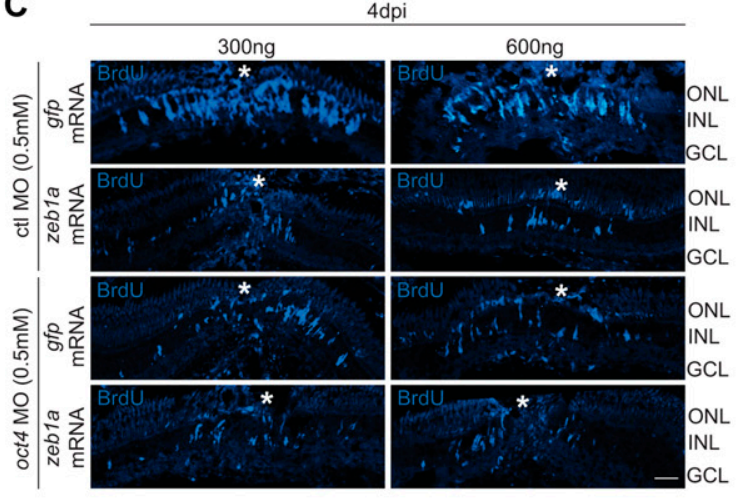

$\mathbf{F}$

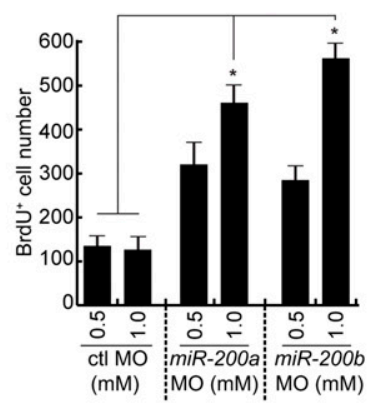

G

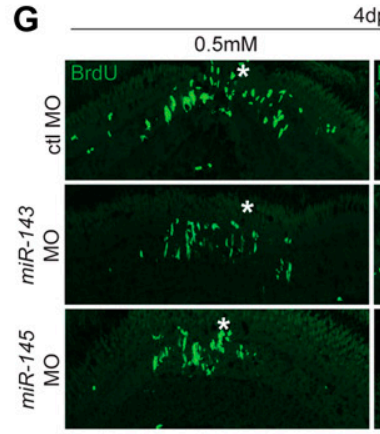

cdh1 MO
I

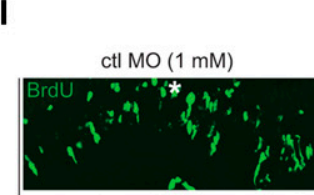

믐
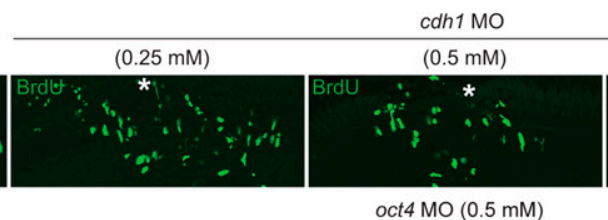

oct $4 \mathrm{MO}(0.5 \mathrm{mM})$

cdh1 $\mathrm{MO}(0 \mathrm{mM})$

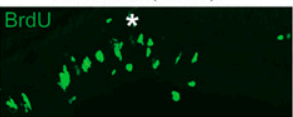

cdh1 $\mathrm{MO}(0.25 \mathrm{mM})$

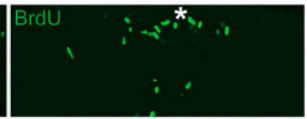

. dpi

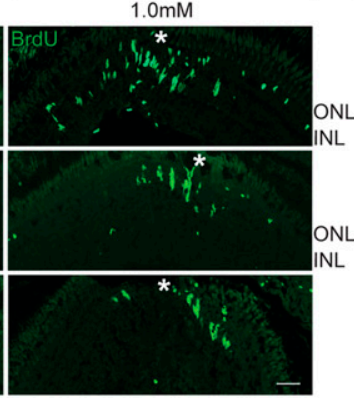

E

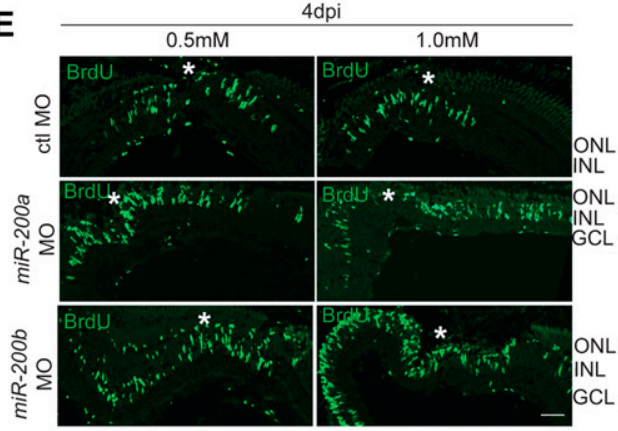

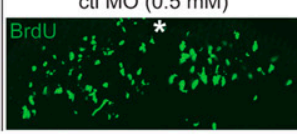

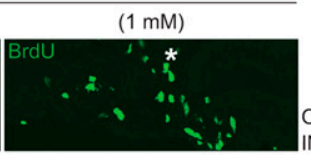

cdh1 $\mathrm{MO}(0.5 \mathrm{mM})$

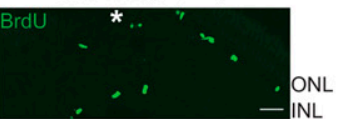

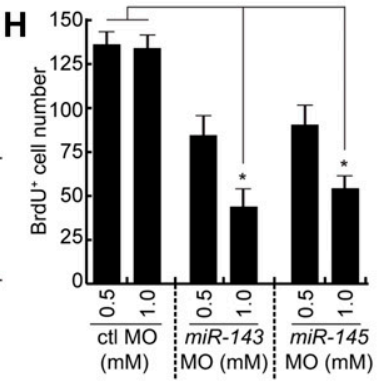

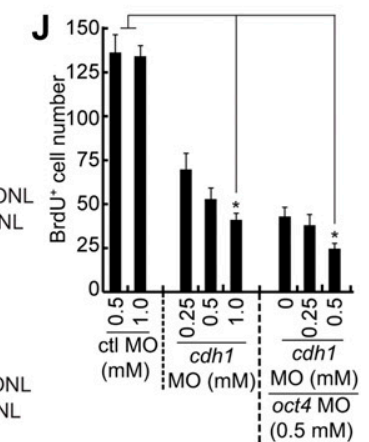

Figure 4. Involvement of Snails, Zebs, miR200a/miR-200b/miR-143/miR-145, and Cdh1 to ensure adequate number of MGPCs during retina regeneration. (A, B) IF confocal microscopy images of 4 dpi retinal cross sections show BrdU MGPCs in snai1a, snai1b, snai2, and snai3 mRNA-transfected conditions along with gfp mRNA-transfected control retina (A), which are quantified (B); ${ }^{*} P<0.002$ ( $t$ test), $N=4$. (C, D) IF confocal microscopy images of 4 dpi retinal cross sections show BrdU ${ }^{+}$ MGPCs in zeb1a mRNA transfected conditions along with gfp mRNA transfected control retina, with control MO and oct4 MO-electroporated conditions (C), which are quantified ( $D$ ); ${ }^{*} P<0.001$ ( $t$ test), N = 4. (E, F) IF confocal microscopy images of 4 dpi retinal cross sections show BrdU ${ }^{+}$MGPCs in miR-200a/miR-200b MO-electroporated conditions along with control $\mathrm{MO}(\mathrm{E})$, which are quantified $(\mathrm{F}) ;{ }^{*} \mathrm{P}<0.004$ ( $t$ test), $\mathrm{N}=4$. (G, H) IF confocal microscopy images of 4 dpi retinal cross sections show BrdU ${ }^{+}$ 
found dual peaks of expression of Oct4 during retina regeneration in zebrafish, which includes a panretinal expression of oct4 at $16 \mathrm{hpi}$ (Fig $1 \mathrm{~A}$ and $\mathrm{B}$ ). Interestingly, the MO-mediated gene knockdown of oct4 had an inhibitory effect on zeb1a, zeb1b, and zeb2a, whereas an up-regulation was seen with regards to miR-200a and miR-200b gene expressions at $2 \mathrm{dpi}$ (Fig $3 \mathrm{~F}$ and $\mathrm{H}$ ). These results suggested that the initial panretinal Oct4 expression contributed to the MG reprogramming through the up-regulation of Zeb family members and down-regulation of miR-200a/miR-200b/miR-143/miR-145 in the retina.

As we have already found increased levels of snail gene family members, namely, snai1a, snai1b, snai2, and snai3 and Tgf- $\beta$ signaling components, such as tgfbr1b, tgfb2, and its effector genes tgfbi and smad7 in oct4 knockdown background (Fig 3B and $\mathrm{C}$ ), we also decided to examine the levels of these genes in oct4-overexpressed retina. We found an anticipated downregulation of Tgf- $\beta$ signaling components (Fig $5 \mathrm{H}$ ) and snail genes (Fig 5l), which is suggestive of an Oct4-dependent Tgf- $\beta$ signaling pathway that is active during retina regeneration. The double mRNA ISH of oct4 and tgfbi, a Tgf- $\beta$ signaling downstream gene, showed a relatively less frequent co-expression pattern in 4 dpi retina and a significant proportion of oct 4 expressing cells lacked tgfbi (Fig S4G). This observation also supported the view that Oct4 had a negative influence on Tgf- $\beta$ signaling during retina regeneration.

Tgf- $\beta$ signaling is known to suppress reprogramming ( $\mathrm{Li}$ et al, 2010) and also suppress E-cadherin through Snails (Batlle et al, 2000). As we found a regulatory relationship of Oct4 with Tgf- $\beta$ signaling, we explored if the cdh1 levels also were affected in response to oct4 overexpression. E-cadherin is a molecule that increases cellular proliferation (Park et al, 2017) and enables cellular adherence (van Roy \& Berx, 2008), which is essential during MET (Wells et al, 2008). We saw a decline in cdh1 mRNA levels in response to oct4 overexpression in $2 \mathrm{dpi}$ retina (Fig 5J). In agreement with the demonstrated decrease in MGPCs because of cdh1 knockdown (Fig $4 \mathrm{l}$ and J), we presume that similar events could occur in Oct4-overexpressed retina wherein a dose-dependent down-regulation of $c d h 1$ is seen, along with lesser propensities of $M G$ to switch into a proliferative phase.

Furthermore, the overexpression of Oct4 also caused a reduction in the expression of lin28a (Fig 5K) and an anticipated up-regulation in let-7a miRNA levels (Fig 5L) in 2 dpi retina. Interestingly, oct4 mRNA transfection caused an up-regulation of ascl1a mRNA (Fig S4H and I) without causing a concomitant increase in its protein levels (Fig S4J), which is probably because of elevated levels of let-7 miRNA, known to block the translation of ascl1a mRNA during retina regeneration (Ramachandran et al, 2010a; Mitra et al, 2018). These observations also support the idea that let-7a miRNA-mediated gene repression events would be crucial in contributing to the reduced MGPCs proliferation in Oct4 overexpressed retina.

\section{Oct4 is essential to bring an end to proliferative phase of MGPCs}

Earlier observations showed a dual peak of expression of Oct4 in the injured retina and its differential collaboration with Hdac1 towards the late phase of regeneration. These observations prompted us to investigate whether Oct4 played alternative roles towards the end of the proliferative phase of retina regeneration. To explore this, we adopted a late gene knockdown approach at a time soon after the peak of proliferation seen at $4 \mathrm{dpi}$. We delivered oct4-targeting $\mathrm{MO}$ at the time of injury and electroporated later at $5 \mathrm{dpi}$ and gave a BrdU pulse at $6 \mathrm{dpi}$. The retinae were harvested at $16 \mathrm{dpi}$ as per the experimental timeline (Fig S5A). The rationale behind this experiment was to see if there is a continuation of active proliferation that occurs in the retina after oct 4 knockdown. Surprisingly, compared with the control MO-electroporated retina, we saw an increased number of BrdU-labeled cells (Fig S5B and C). These results could be due to two possible scenarios: (i) more MG cells enter the cell cycle and (ii) the BrdU ${ }^{+}$MGPCs fail to exit the cell cycle and continue to be in the proliferative phase. To decipher which of these options prevailed in the late oct4 knockdown retina, we adopted another experimental approach with an early BrdU and late EdU labeling of MGPCS. In an experimental timeline (Fig S5D), oct4 MO was delivered at the time of injury followed by a BrdU pulse at $5 \mathrm{dpi}$, and electroporation after $3 \mathrm{~h}$. The retinae were harvested at $8 \mathrm{dpi}$ after $3 \mathrm{~h}$ of EdU pulse. Interestingly, compared with the control MO-electroporated retina, we saw a MO concentration-dependent increase in the number of $\mathrm{EdU}^{+}$cells, which were also marked with BrdU in oct4 knockdown retina at 8 dpi (Figs 6A-C, and S5D and E). We did not find a significant number of $\mathrm{EdU}^{+}$cells that were not labeled with BrdU. These results supported the idea that the late knockdown of oct4 from 5 to 8 dpi makes the MGPCs continue to proliferate. Early knockdown of oct4 had an anti-proliferative effect with an associated increase in Tgf- $\beta$ signaling component genes. Here, contrary to early inhibition of Oct4 (Fig $3 B$ and C), its late knockdown regime (Fig $6 \mathrm{~A}$ ) had a negative influence on the Tgf- $\beta$ signaling components (Fig 6D) and snail gene family members (Fig $6 \mathrm{E})$, which also support the observed increase in MGPCS.

Moreover, we observed such a late knockdown of oct 4 was also associated with up-regulation of various cell cycle-specific genes such as cyclins, delta family members (Fig S5F), essential cytokines (Fig S5G) (Zhao et al, 2014; Mitra et al, 2018), and regenerationassociated transcription factors, namely, ascl1a, mycb, oct4, sox2, lin28a, and matrix metalloproteinases such as mmp2 and $\mathrm{mmp}$. (Fig 6F). The oct4 late knockdown had a profound effect on the down-regulation of let-7a miRNA levels (Fig 6G) that could be the effect of up-regulated lin28a (Figs 6F and S5H), which is known to facilitate MGPCs proliferation (Ramachandran et al, 2010a; Kaur et al, 2018). Similarly, the observed up-regulation of regenerationassociated transcription factors with late oct4 knockdown at $8 \mathrm{dpi}$ (Fig 6F) was also reflected in Western blot analysis (Fig 6H) and its quantification (Fig 6I). Based on these observations, we speculated

MGPCs in miR-143/miR-145 MO-electroporated conditions along with control MO (G), which are quantified ( H); * $P<0.01$ ( $t$ test), N = 4. (I, J) IF confocal microscopy images of $4 \mathrm{dpi}$ retinal cross sections show BrdU ${ }^{+} \mathrm{MGPCs}$ in $c d h 1 \mathrm{MO}$-electroporated conditions along with control $\mathrm{MO}$ and oct4 $\mathrm{MO}(\mathrm{I})$, which are quantified (J); ${ }^{*}<0.003$ ( $t$ test), $\mathrm{N}=$ 4. Ctl MO is control MO. Error bars are SD. (A, C, E, G, I) Scale bars, $10 \mu \mathrm{m}$; the asterisk marks the injury site; GCL, ganglion cell layer; INL, inner nuclear layer; ONL, outer nuclear layer (A, C, E, G, I). 
A

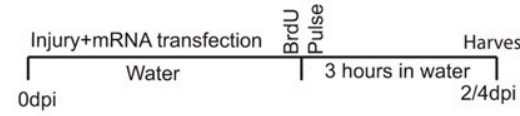

B

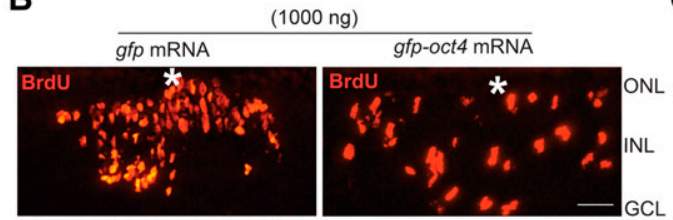

C

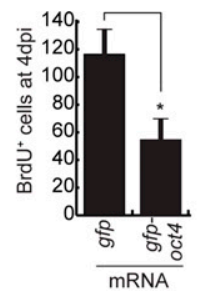

D

$4 \mathrm{dpi}$

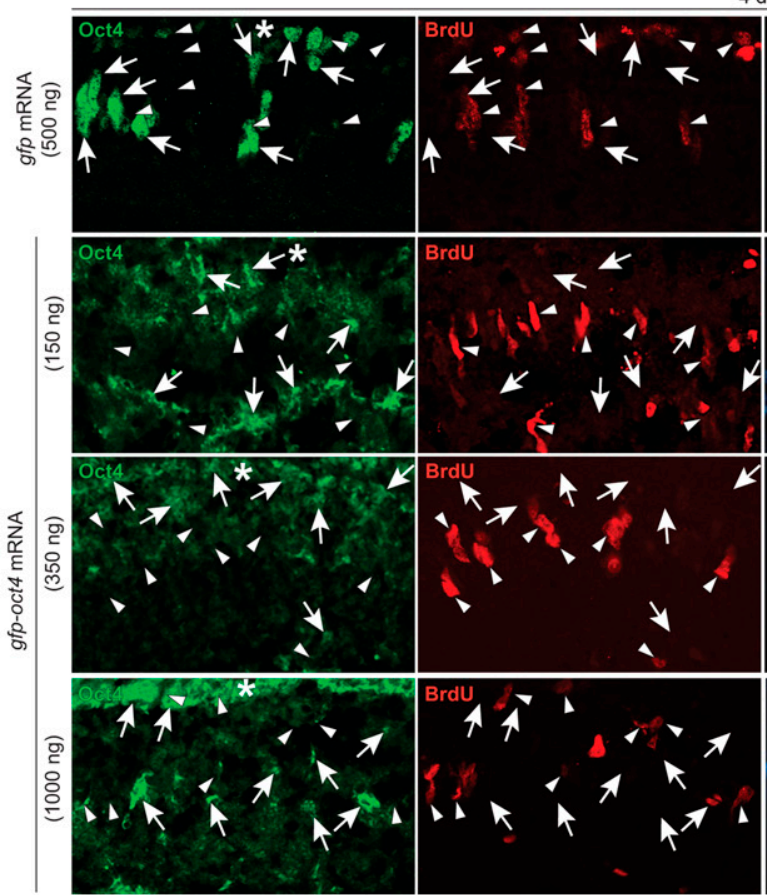

E

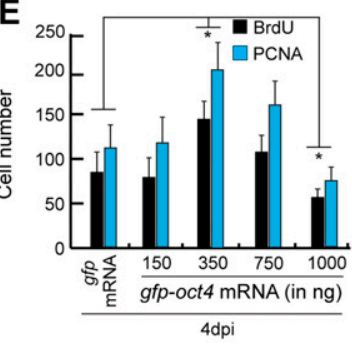

I

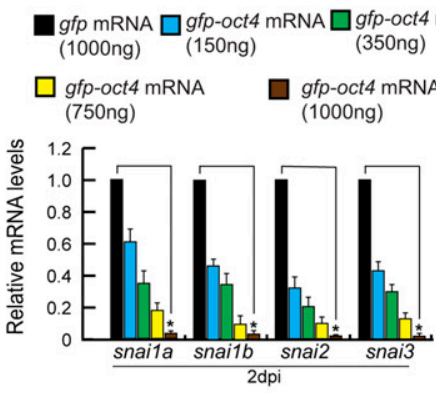

$\mathbf{F}$

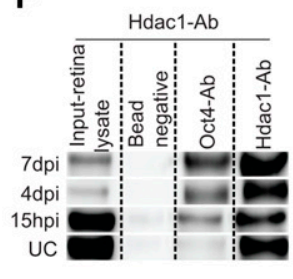

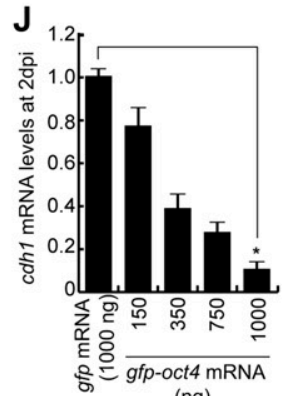

G

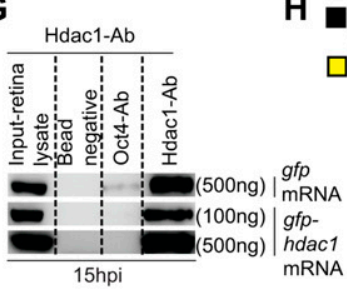

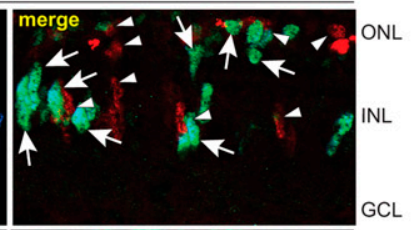
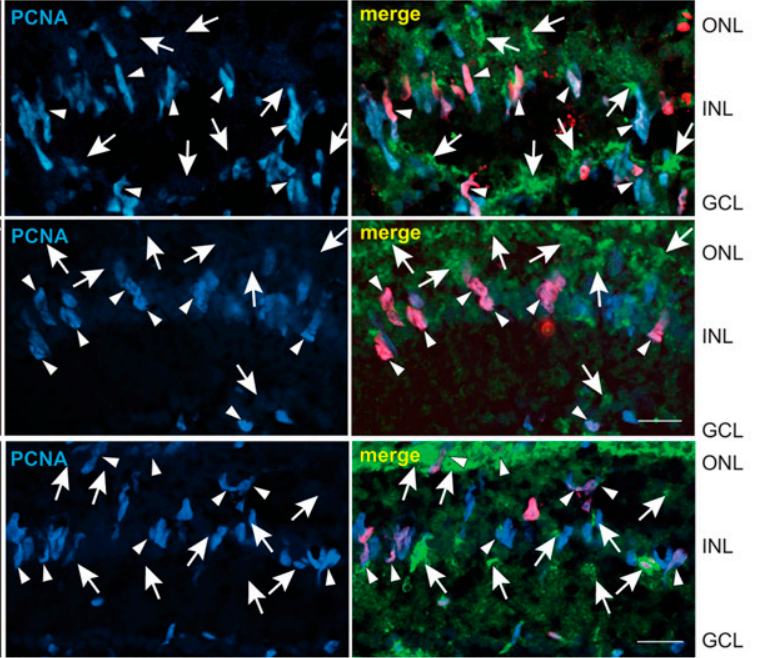

H gfp mRNA $\square$ gfp-oct4 mRNA $\square$ gfp-oct4 mRNA (1000ng) (150ng) (350ng)

gfp-oct4 mRNA gfp-oct4 mRNA

(750ng) (1000ng)

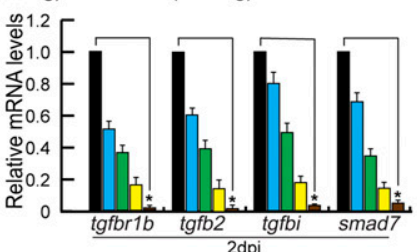

K

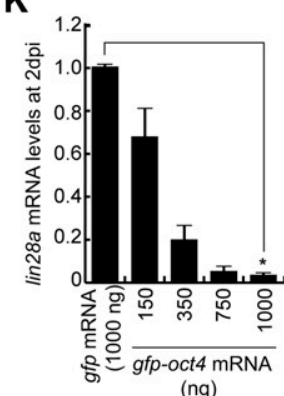

Figure 5. Effect of Oct4 overexpression in the injured retina.

(A) An experimental timeline that describes the mRNA transfection and BrdU pulse (for 4 dpi collection) before harvesting either at 2 or 4 dpi. (B, C) IF confocal microscopy images of retinal cross sections show reduced BrdU ${ }^{+}$MGPCs at $4 \mathrm{dpi}$ in oct4 mRNA transfected condition, compared with gfp mRNA-transfected control retina (B), which is quantified (C); ${ }^{*}<0.0001$ ( $t$ test), $N=4$. (D) IF confocal microscopy images of retinal cross sections of oct 4 mRNA-transfected retina at 4 dpi shows the cells with strong expression of Oct 4 having a significant seclusion from PCNA $/ \mathrm{BrdU}^{+}$MGPCs. White arrowheads mark BrdU $/ \mathrm{PCNA}^{+}$cells and white arrows mark Oct4 ${ }^{+}$cells. (E) Quantification of BrdU ${ }^{+}$and PCNA ${ }^{+}$cells from oct4-overexpressed retina. (F) Western blot analysis of Co-IP of Oct4 and Hdac1 in retinal extracts at various time points postinjury probed with anti-Hdac1 antibody. (G) Western blot analysis of Co-IP of Oct4 and Hdac1 in retinal extracts obtained after hdac1 overexpression at 15 hpi and 
that Oct4 might be acting as a transcriptional repressor for several regeneration-associated genes during late phases of retina regeneration. These results also suggest that Oct4 may contribute to the regulation of component genes of repressive assembly such as NuRD complex.

\section{Oct4-NuRD interplay is essential for cell cycle exit of MGPCs}

NuRD complex-mediated gene repressive events have been previously shown to be important for cellular differentiation ( $\mathrm{Hu}$ \& Wade, 2012). Here, because of late oct4 knockdown, we found an increase in proliferation of MGPCS, which could result from a lack of NuRD complex-mediated gene repressive events. For this, we explored if the late oct4 knockdown had any influence on the member genes of NuRD complex. Analysis of the gene family members encoding chromodomain helicase and DNA binding protein (Chd), namely, chd3, chd4a, and chd4b, along with hdac1 that are members of NURD complex showed a decline in late oct4 knockdown retina (Fig 7A and B). This observation is supported by Oct4 binding onto the regulatory sequences of hdac1 and chd4a genes, as revealed in ChIP assay (Fig 7C and D).

Furthermore, based on the above observations, we speculated that during the differentiation phase, Oct4 might alter its function from gene activation to repression through collaboration with Hdac1. To test this further, we adopted a late hdac1 knockdown approach similar to the experimental timeline (Fig 7A). We found a similar increase in $\mathrm{EdU}^{+} \mathrm{MGPCS}$ as found with late oct4 knockdown, suggesting the involvement of Oct4-Hdac1 complex in gene repression events (Fig 7E and F). Notably, the late hdac1 knockdown also caused a significant up-regulation of various regenerationassociated transcription factors, namely, ascl1a, mycb, oct4, sox2, lin28a, and matrix metalloproteinases such as $\mathrm{mmp} 2$ and $\mathrm{mmp} 9$ (Fig 7G), similar to what we found in late oct4 knockdown. The regulatory DNA sequences of some of these transcription factors also had typical Oct4-BS. Furthermore, to explore if Hdac1 occupied these Oct4-BS, we performed a ChIP assay using Hdac1 antibody in the retinal extract from 6 dpi. Interestingly, Hdac1 occupied the Oct4-BS present on ascl1a (Fig $7 \mathrm{H}$ ) and oct4 (Fig $7 \mathrm{l})$ gene promoters only in 6 dpi but not in 16 hpi retina (Fig $7 \mathrm{H}$ and I). Furthermore, overexpression of Hdac1 through mRNA transfection did not cause any change in its affinity for Oct4-BS on ascl1a and oct4 promoters in 16 hpi retina (Fig $7 \mathrm{H}$ and I).

Notably, the late hdac1 knockdown-mediated up-regulation of lin28a probably facilitated a decline in the let-7a miRNA levels (Fig 7)). The reduced levels of let-7a would also allow efficient translation and elevated protein levels of several regenerationassociated transcription factors (Fig 7K), also reflected by its quantification (Fig $7 \mathrm{~L}$ ). These results support the view that Oct4Hdac1 complex contributes to the down-regulation of various regeneration-associated factors towards the late phases of regeneration. Such a regulation supports the view that the increased $\mathrm{EdU}^{+}$cells seen in the late oct4 knockdown retina are the result of a genuine proliferative response of MGPCs. This type of differential influence of Oct4 at various stages of regeneration is probably mediated through its interaction with selective collaborating partners such as members of the NuRD complex.

We further explored if the increased number of MGPCs formed during the late oct4 knockdown were able to differentiate into various retinal cell types. For this, a lineage tracing of these persistently proliferating MGPCS was performed by labeling with BrdU and their fate was followed up to $30 \mathrm{dpi}$. The cell type-specific staining and co-labeling with BrdU revealed that these MGPCs were indeed capable of differentiation (Fig S6B-D). We further confirmed these results by counting the number of BrdU-labeled cells that migrated to various retinal layers at $30 \mathrm{dpi}$ (Fig 7M-O). These results support the significance of the Oct4-mediated gene regulatory network to cause cell cycle exit of MGPCs during retina regeneration.

\section{Discussion}

Despite the knowledge on the expression patterns of PIFs soon after injury in the zebrafish retina, the roles played by Oct4 remained underexplored. In the present study, we delved into the significance of the induction of Oct4 soon after injury. We found differential roles played by Oct4 to cause a robust regenerative response in collaboration with a plethora of molecules, including transcription factors, components of Tgf- $\beta$ signaling, miRNAs, and NuRD complex. Oct4 is one of the six PIFs that significantly influence several signaling pathways, which are necessary during cellular reprogramming in mammalian systems (Radzisheuskaya \& Silva, 2014). As previously reported, the important regulatory network mediated by Oct4 during cellular reprogramming includes (i) repression of Tgf- $\beta$ signaling (Li et al, 2010; Tan et al, 2015), (ii) activation of the miR-200 family of miRNAs, which are the repressors of Zeb family of transcription factors (Wang et al, 2013), and (iii) epigenetic regulation of various genes responsible for cellular reprogramming in collaboration with Sox2 and Klf4 (Soufi et al, 2012; Buganim et al, 2013; Papp \& Plath, 2013). Here, we explored if similar pathways ensue in the reprogramming of $M G$ as a part of regeneration. The detailed findings from this study are summarized and depicted in a model (Fig 8).

We found a panretinal expression of oct4 soon after retinal damage, which stays restricted to the site of injury throughout the proliferative cascade and secluded from the actively proliferating MGPCS. Closer analysis revealed that Oct4 induction during the proliferative phase of regeneration is a feature of MGPCS that quit the cell cycle. In spite of the report that Oct4 may not be important for somatic stem cell renewal (Lengner et al, 2007), studies in the injured mice retina that fails to regenerate showed an immediate induction of Oct4, which also declined quickly (Reyes-Aguirre \& Lamas, 2016). However, in zebrafish, the dual expression peak of Oct4 at 16 hpi and $4 \mathrm{dpi}$ in injured retina gave us critical clues about

probed with anti-Hdac1 antibody. (H, I, J, K, L) The qRT-PCR analysis reveals the levels of tgfbr1b, tgfb2, tgfbi, smad7 (H), snails (I), cdh1 (J), lin28a (K), and let-7a miRNA (L) in oct4 mRNA-transfected retina at $2 \mathrm{dpi}$; ${ }^{*} P<0.001$ ( $t$ test), $\mathrm{N}=4$. Error bars are SD. (B, D) Scale bars, $10 \mu$ m; the asterisk marks the injury site; $\mathrm{GCL}$, ganglion cell layer; INL, inner nuclear layer; ONL, outer nuclear layer (B, D). 
A

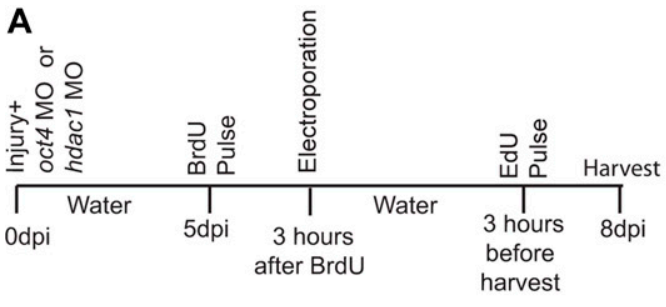

D

$\square$ Ctl MO-8dpi

$\square$ oct4 $\mathrm{MO}$

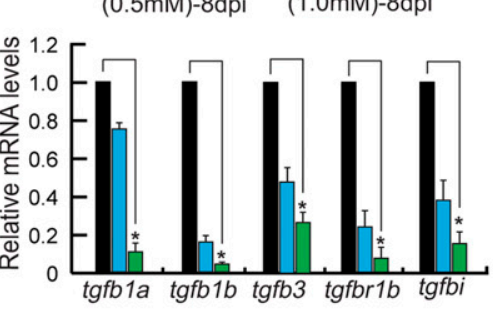

E

CtI MO-8dpi

oct $4 \mathrm{MO}$

(0.5mM)-8dpi (1.0mM)-8dpi

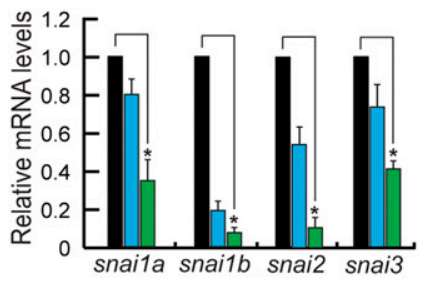

F

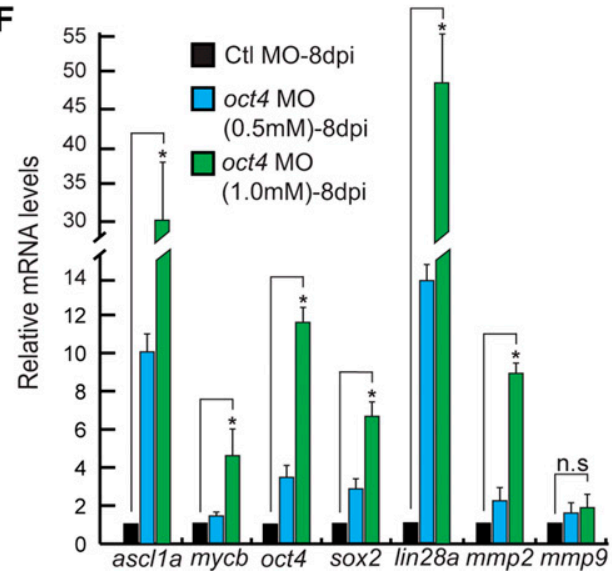

B

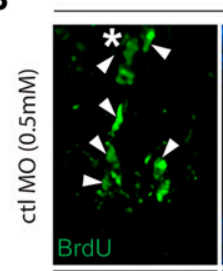

8dpi

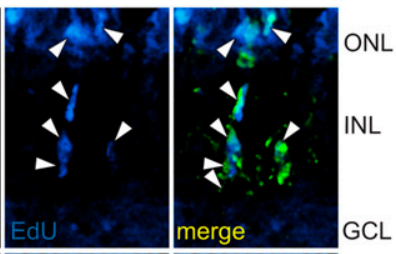

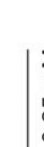
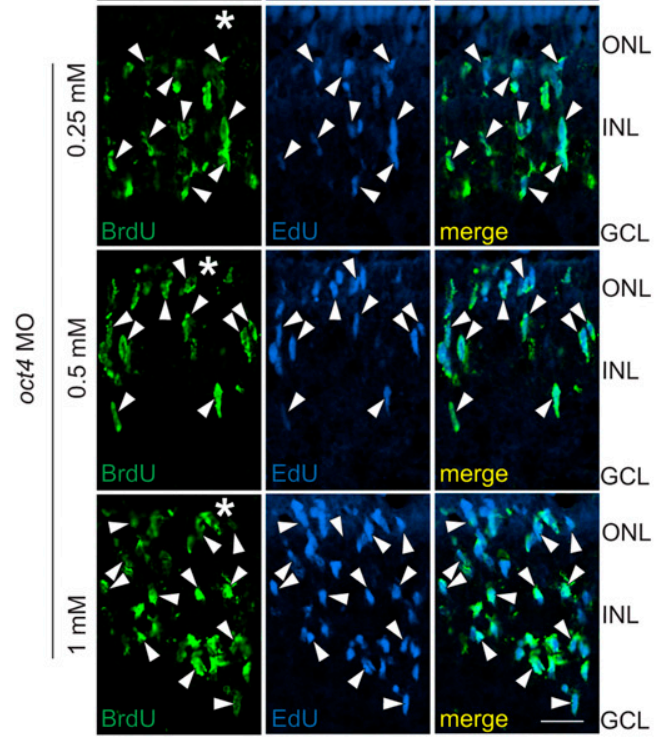
merge

G

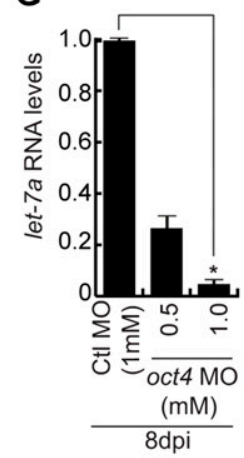

C

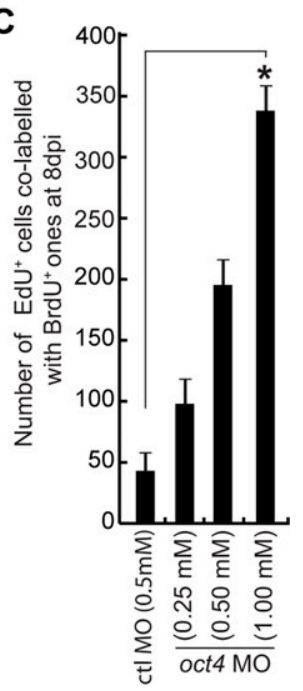

Figure 6. The increased MGPCs seen in late oct4 knockdown in regenerating retina is caused by the delay in cell cycle exit.

(A) An experimental timeline that describes the injury, MO injection, BrdU pulse, late electroporation of the retina, and EdU pulse $3 \mathrm{~h}$ before harvest at $8 \mathrm{dpi}$ (B, C) IF confocal microscopy images of retinal cross sections show increased BrdU $\mathrm{MGPCS}^{+} \mathrm{dt}$ d in oct4 knockdown from fifth day onwards and a proof of the delay in quitting cell cycle revealed by EdU co-labeling with BrdU ${ }^{+} \mathrm{MGPCS}(\mathrm{B})$, which is quantified (C); ${ }^{*} \mathrm{P}<0.001, \mathrm{~N}=4$. White arrowheads mark BrdU ${ }^{+} / \mathrm{EdU}^{+}$cells in (B). (D) qRT-PCR analysis of Tgf- $\beta$ signaling component genes and its reporter tgfbi mRNA levels in late oct4 knockdown retina, at 8 dpi; ${ }^{*} P<0.02$ ( $t$ test), $N=4$. (E) qRT-PCR analysis of snail family genes' mRNAs in late oct4 knockdown retina, at $8 \mathrm{dpi}$; ${ }^{*} \mathrm{P}<0.03$ ( $t$ test), $\mathrm{N}=4$. (F) qRT-PCR analysis of ascl1a, mycb, oct4, sox2, lin28a, $m m p 2$, and $m m p 9$ mRNA levels in late oct4 knockdown retina, at 8 dpi. (G) qRT-PCR analysis of let-7a miRNA levels show a decline because of oct4 late knockdown in 8 dpi retina. (H, I) Western blot analysis of 
its importance and the possible existence of differential roles at early and late phases of regeneration. This led us to explore whether Oct4 performed similar or different roles during zebrafish retina regeneration in comparison with mammalian cellular reprogramming. We found the necessity of Oct 4 during the early stages of retina regeneration to keep the Tgf- $\beta$ signaling at bay, which is similar to the mammalian system. Tgf- $\beta$ signaling is also known to be anti-proliferative during retina regeneration in various model organisms (Close et al, 2005; Lenkowski et al, 2013; Todd et al, 2017). In mammalian cellular reprogramming, Oct4 activates miR200 family (Radzisheuskaya \& Silva, 2014), which is the repressor of zeb mRNAs (Park et al, 2008). Surprisingly in the zebrafish retina, we saw the direct binding of Oct4 on the promoters of miR-200 and zeb family of genes resulting in repression of the former and activation of the latter. Moreover, considering the repressive role of miR-200 on zeb mRNAs, one could presume that Oct4 ensures high levels of Zeb proteins in the early stages of retina regeneration. More importantly, the panretinal induction of Oct4 ensures elevated levels of zeb, probably to avoid reprogramming of MG away from the site of injury. Evidence for this is also seen in 1016tuba1a:GFP transgenic retina wherein the GFP- cells express higher levels of zeb than the $\mathrm{GFP}^{+}$ones. Our overexpression studies of zeb1a and zeb2a in regenerating retina also confirmed their anti-proliferative nature as seen in cancer cells (Hugo et al, 2013). Similarly, the proliferating group of MGPCs also have cells that are about to differentiate and also the ones which would continue to be in the cell cycle for a prolonged time. Here too, the actively proliferating MGPCs have less Oct4 ensuring their persistence in the cycling phase, and the cells that are about to differentiate have relatively more Oct4 expression, which in turn activates pathways that block cell division or further reprogramming. This scenario is evident from the lack of proliferation in Zeb/Snail overexpressed retina.

Furthermore, it is interesting to note that Oct4 had a repressive role on miR-200a/miR-200b and miR-143/miR-145, which are antiproliferative and pro-proliferative in nature, respectively. Although it may appear to be a conundrum, this type of transcriptional regulation of miRNAs by Oct4 ensures adequate $M G$ reprogramming and induction of MGPCS, a situation otherwise could have led to undesirable cellular proliferation. In addition, we also showed that the Oct4 negatively influenced the E-cadherin in regenerating retina, unlike reported in the mammalian adult stem cells and during MET (Radzisheuskaya \& Silva, 2014; An et al, 2017). The decreased zeb levels in early oct4 knockdown conditions also could contribute to the elevated cdh1 (E-cadherin) levels. The higher levels of Oct4 in post-proliferative MGPCS inevitably deemed them to adopt a cell differentiation cascade than a reprogramming one, justifying the observed results. These findings are also supported by the retinal Oct4 overexpression performed in this study. The MOmediated knockdown of cdh1 in isolation or in combination with oct4 MO had a negative effect on MGPCS proliferation. It is also important to note that E-cadherin is known to promote neurite outgrowth from retinal ganglion cells (Oblander et al, 2007) and cellular proliferation in certain cancers (Dong et al, 2012). These observations suggest that an increase in cdh1 levels in oct4 knockdown retina was not able to complement the absence of Oct4 and the decline in the levels of $c d h 1$ alone was sufficient to hinder MGPCS induction.

We discovered that the significance of Oct4 during retina regeneration seemed to be multifactorial at various phases of retina regeneration, which is revealed from our early and late knockdown experiments of Oct4. In other words, the early oct4 knockdown soon after the injury had an anti-proliferative effect, whereas the late one had a pro-proliferative effect on MGPCs. Furthermore, the overexpression of Oct4 through mRNA transfection of the retina had a negative effect on proliferation, especially with higher concentration. Also, the overexpression of hdac1, one of the collaborators of Oct4, abolished the Hdac1-Oct4 interaction and this also accelerated the MGPC proliferation in the retina, suggesting the necessity of selective extent of collaboration of Oct 4 with its partners in regulating a particular gene target. It is also important to note that zebrafish Oct4 failed to support murine embryonic stem cell self-renewal (Morrison \& Brickman, 2006) probably because of its differential effects in comparison with mammalian counterpart. This opened up the scenario for us to explore the intricate details about the components of the Oct4-mediated regulatory network at different phases of retina regeneration.

Our study showed that Oct4 played differential roles in regulating the proliferation of MGPCS at various phases of retina regeneration. Closer analysis revealed that the MGPCs that are formed during regeneration failed to quit the cell cycle and continue to be in the proliferative phase in late oct4 knockdown. At later stages, Oct4 switches its activating function on genes that facilitate cell proliferation to their suppression in collaboration with Hdac1, a member of NuRD complex. Oct4 positively regulated the transcriptional repressor Her4.1 to keep lin28a at bay in cells that exit cell cycle. Furthermore, the up-regulation of lin28a and a decline in the let-7a miRNA levels in late oct4 knockdown could also facilitate the translation of regeneration-associated factors as previously demonstrated (Ramachandran et al, 2010a; Kaur et al, 2018). In conclusion, our results illustrated various mechanisms of retina regeneration mediated through the PIF, Oct4. This study also opens up new vistas of exploration in similar lines that would enable designing therapeutic strategies to cure mammalian retinal blindness.

\section{Materials and Methods}

\section{Animals}

Zebrafish were maintained at $26^{\circ} \mathrm{C}-28^{\circ} \mathrm{C}$ on a $14: 10 \mathrm{~h}$ light/dark cycle. The 1016tuba1a:GFP transgenic fish used in this study have been previously characterized (Fausett \& Goldman, 2006). Embryos for microinjection in Luciferase assays were obtained by natural breeding of wild-type fish.

various regeneration-associated factors in late oct4 knockdown retina at $8 \mathrm{dpi}$, which is quantified by densitometry (I). Gapdh is used as the loading control. Ctl $\mathrm{MO}$ is control MO. Error bars are SD. (B) Scale bars, $10 \mu \mathrm{m}$; the asterisk marks the injury site; GCL, ganglion cell layer; INL, inner nuclear layer; ONL, outer nuclear layer (B). 
A

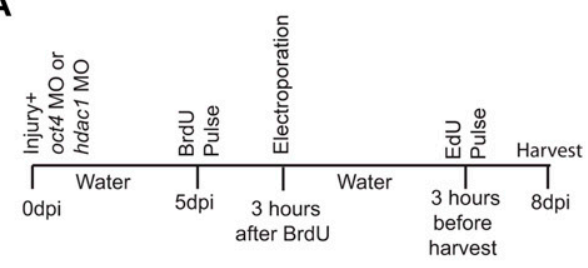

D

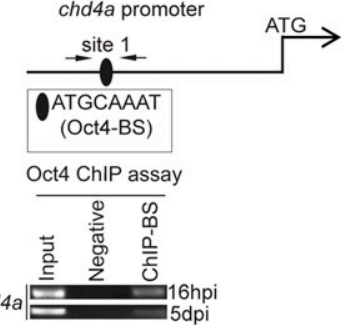

E
B
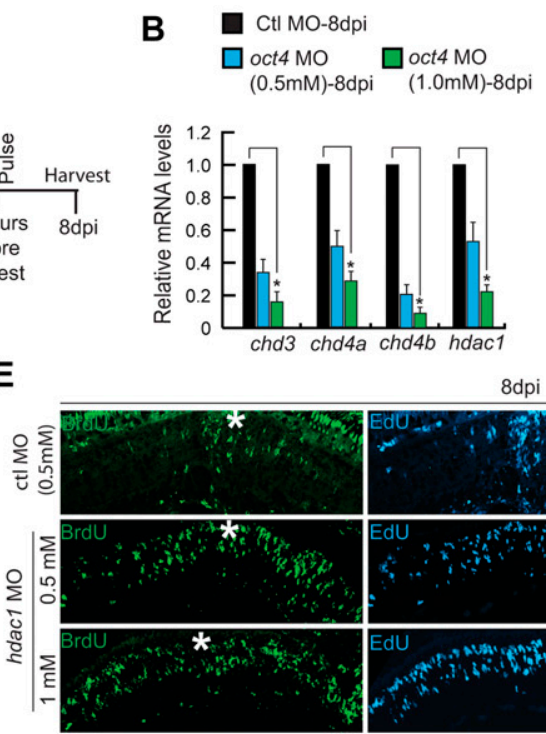

$8 \mathrm{dpi}$
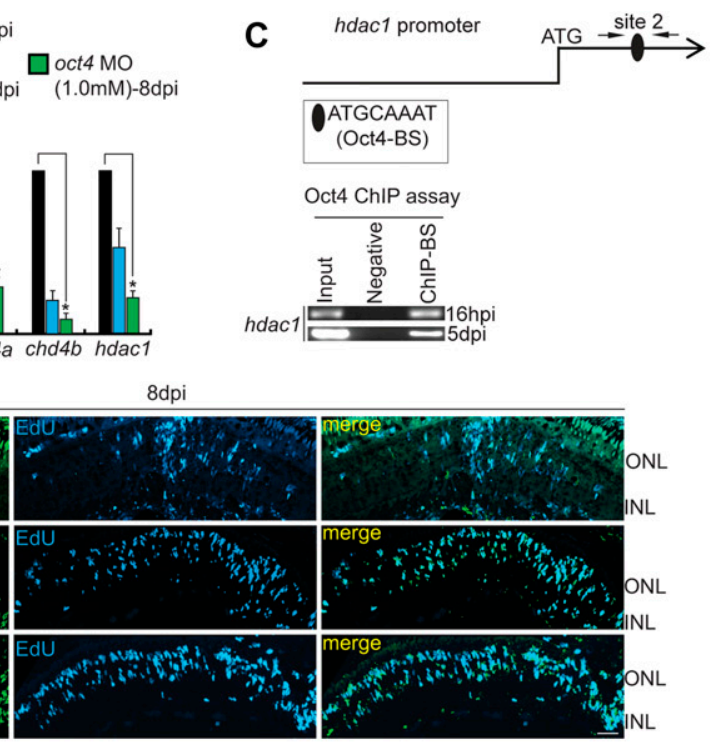

F

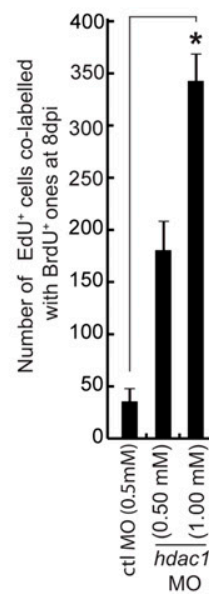

G

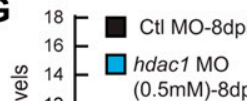

竞 $14-2-(0.5 \mathrm{mM})-8 \mathrm{dpi}$

$\frac{\text { o }}{4} 12-\square$ hdac1 MO

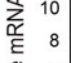

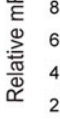

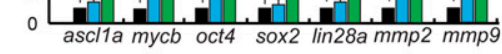

Hdac1 ChIP assay on Oct4-BS

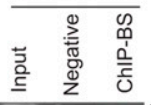

I oct4 promoter (OAGCAAAT
(OCt4-BS)

M Injury+

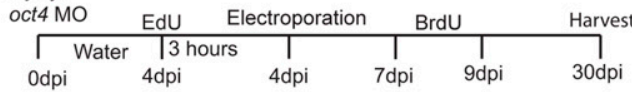

N

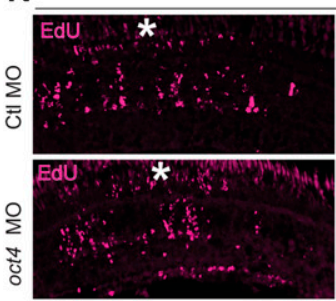

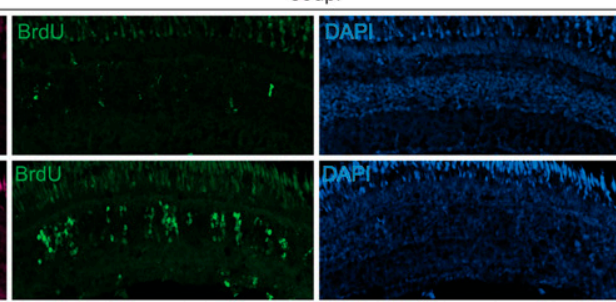

H
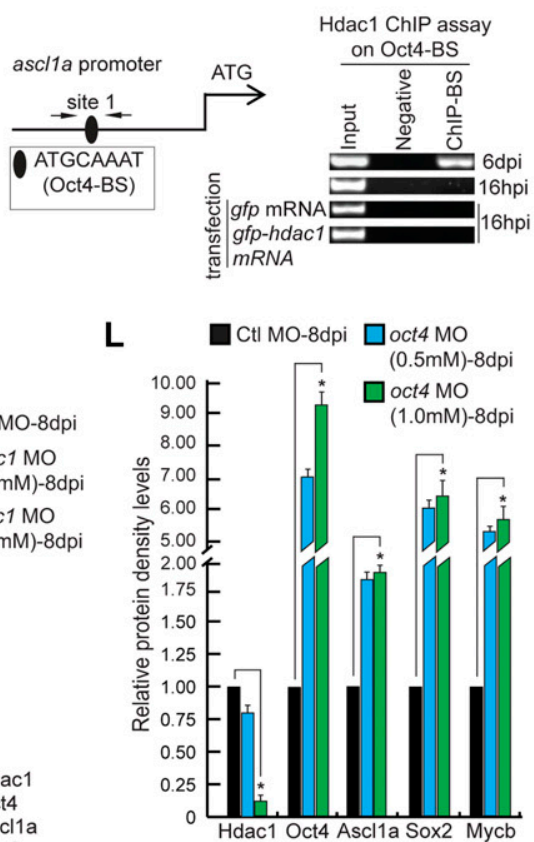

Figure 7. Effect of late hdac1 and oct4 knockdowns on MGPCs and gene expressions.

(A) An experimental timeline that describes the injury, MO injection, BrdU pulse, late electroporation of the retina, and EdU pulse $3 \mathrm{~h}$ before harvest at $8 \mathrm{dpi}$. (B) qRT-PCR analysis of NuRD complex component genes' mRNA levels in late oct4 knockdown retina, at 8 dpi. (C, D) The hdac1 (C) and chd4a (D) promoter schematics reveal the typical Oct4-BSs (upper) and the retinal ChIP assays confirm the physical binding of Oct4 at these sites (lower), in 16 hpi and 5 dpi retina. (E, F) IF confocal microscopy images of retinal cross sections show increased BrdU ${ }^{+}$MGPCS at 8 dpi in hdac1 knockdown from fifth day onwards and the delay in exiting cell cycle as revealed by EdU co-labeling with BrdU ${ }^{+}$MGPCs (E), which is quantified (F). (G) qRT-PCR analysis of ascl1a, mycb, oct4, sox2, lin28a, mmp2, and mmp9 mRNA levels in late hdac1 knockdown 


\section{Anesthesia and retinal injury}

Fish were anesthetized with tricaine methanesulfonate. The retinal injury was performed with a $30 \mathrm{G}$ needle as described previously (Fausett \& Goldman, 2006). All experiments were performed to a minimum of four times for consistency and s.d.

\section{Primers and plasmid construction}

All primers are listed in Table S1. The ascl1a:GFP-luciferase construct was described previously (Ramachandran et al, 2010a; Wan et al, 2012). Full coding sequence (CDS) of oct4, hdac1, snai1a, snai1b, snai2, snai3, zeb1a, and zeb2a were cloned by PCR amplification of CDNA prepared from RNA of $24 \mathrm{~h}$ postfertilization zebrafish embryos, using their respective primer pairs. Postdigested PCR amplicons of oct4 and hdac1 were cloned in $\mathrm{pCS} 2^{+}-\mathrm{GFP}$, whereas the zeb1a, zeb2a, and snail were cloned in $\mathrm{pCS2}^{+}$. The $\mathrm{pCS2}^{+}$-GFP plasmid was described earlier (Mitra et al, 2018, 2019).

\section{mRNA synthesis and embryo microinjection}

Gene clones of oct4, hdac1, snai1a, snai1b, snai2, snai3, zeb1a, and zeb2a-CDS were linearized and capped mRNAs were synthesized using the mMESSAGE mMACHINE SP6 (AM1340; Thermo Fisher Scientific) in vitro transcription system. For luciferase assays, single-cell zebrafish embryos were injected with a total volume of $\sim 1 \mathrm{nl}$ solution containing $0.02 \mathrm{pg}$ of Renilla luciferase mRNA (normalization), $5 \mathrm{pg}$ of promoter:GFP-luciferase vector and 0-6 pg of oct4 mRNA or 0.1-0.5 mM oct4 MO. To assure consistency of results, a master mix was made for daily injections and $\sim 300$ embryos were injected at the single cell stage. After $24 \mathrm{~h}$, the embryos were divided into three groups ( 70 embryos/group) and lysed for dual-luciferase reporter assays (E1910; Promega).

\section{mRNA transfection}

mRNA transfection was performed for in vivo overexpression of oct4, hdac1, snai1a, snai1b, snai2, snai3, zeb1a, and zeb2a, in injured zebrafish retina. Transfection mixture contained two solutions constituted in equal volumes: (i) $4-5 \mu \mathrm{g}$ of mRNA mixed with HBSS, (ii) Lipofectamine messenger max reagent (cat. no. LMRNA001; Invitrogen) mixed with HBSS. Both the solutions were allowed to stand at room temperature for $10 \mathrm{~min}$ and then mixed dropwise followed by 30-min incubation at room temperature. The resultant solution was used for injection in zebrafish retina followed by electroporation as described earlier (Fausett \& Goldman, 2006). The gfp mRNA transfection was performed in control injured retina and in retinae transfected with snails and zebs-mRNA.

\section{MO electroporation and knockdown rescue}

Lissamine-tagged MOs (Gene Tools) of $~ 0.5 \mu \mathrm{l}$ (0.25-1.0 mM) volume were injected, at the time of injury, using a Hamilton syringe of $10 \mu \mathrm{l}$ volume capacity. MO delivery to cells was accomplished by electroporation with five pulses at $70 \mathrm{~V}$ for $50 \mathrm{~ms}$ with a gap period of $950 \mathrm{~ms}$ in between the pulses (Fausett et al, 2008). The fish retinae were assayed for cell death post electroporation and compared with control before proceeding with actual experiments. We did not observe any cell death because of electroporation to the retina. The sequence of control MO has been previously described (Wan et al, 2012). MOs targeting oct4, miRNAs, and cdh1 are as follows:

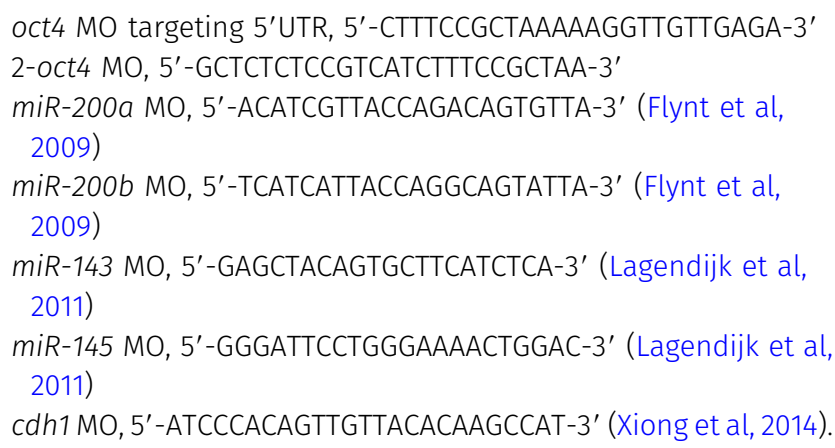

In vivo rescue experiments were designed for testing the specificity of oct4 antisense oligos. We did the transfection of zebrafish retina using oct4-specific mRNA alongside the MO targeting 5' UTR region. For confirming the efficient mRNA transfection, GFP mRNA was also delivered by transfection in control retina along with either oct4 $\mathrm{MO}$ or control MO, whereas GFP fusion with oct4 mRNA was used in other sets.

\section{Total RNA isolation, RT-PCR, and qRT-PCR analysis}

Total RNA was isolated from dark-adapted zebrafish retinae of control, injured, and drug-treated/MO-electroporated/mRNAtransfected groups using TRIzol (Invitrogen). A combination of oligo-dT and random hexamers were used to reverse-transcribe $\sim 5 \mathrm{~g}$ of RNA using Superscript III Reverse Transcriptase (Invitrogen) to generate CDNA. PCR reactions used Taq or Phusion (New England Biolabs) polymerase and gene-specific primers (Table S1) with previously described cycling conditions (Ramachandran et al, 2010a). Quantitative real-time PCR (qRT-PCR) was carried out in triplicate with KOD SYBR (SYBR green containing PCR mix with KOD DNA polymerase from Thermococcus kodakaraensis) qRT-PCR mix (QKD-201; Genetix) on a real-time PCR detection system (MasterCycler RealPlex4; Eppendorf). The let-7a miRNA levels were determined with TaqMan hsa-let7-a probe (Applied Biosystems) as

retina, at $8 \mathrm{dpi}$. $(\mathbf{H}, \mathbf{I})$ The ascl1a $(\mathrm{H})$ and oct4 (I) promoter schematics reveal the typical Oct4-BS (upper) and the retinal ChIP assays confirm the physical binding of Hdac1 at the Oct4-BS (lower) in 6 dpi retina. The ChIP assay performed in 16 hpi retina and also in hdac1-overexpressed condition reveal no binding of Hdac1 at Oct4-BS of ascl1a ( $\mathrm{H}$, right) and oct4 (I, right) promoters. The gfp mRNA transfection is the control. (J) The qRT-PCR analysis shows decreased let-7a miRNA levels with late hdac1 knockdown at 8 dpi. (K, L) Western blot analysis of different regeneration-associated factors in late hdac1 knockdown retina at $8 \mathrm{dpi}$, which is quantified by densitometry (L). Gapdh is used as the loading control. (M) An experimental timeline that describes the injury, MO injection, EdU pulse, and late electroporation of the retina at 4 dpi and BrdU on 7-9 dpi before harvest at $30 \mathrm{dpi}$. (N, 0) IF confocal microscopy images of retinal cross sections show EdU and BrdU-labeled MGPCs in oct4 knockdown from the fourth day onwards and the localization of the BrdU-labeled MGPCS to various retinal layers at $30 \mathrm{dpi}(\mathrm{N})$, which is quantified (O). Ctl MO is control MO. Error bars are SD. (E, N) Scale bars, $10 \mu \mathrm{m}$; the asterisk marks the injury site; GCL, ganglion cell layer; INL, inner nuclear layer; ONL, outer nuclear layer (E, N). 

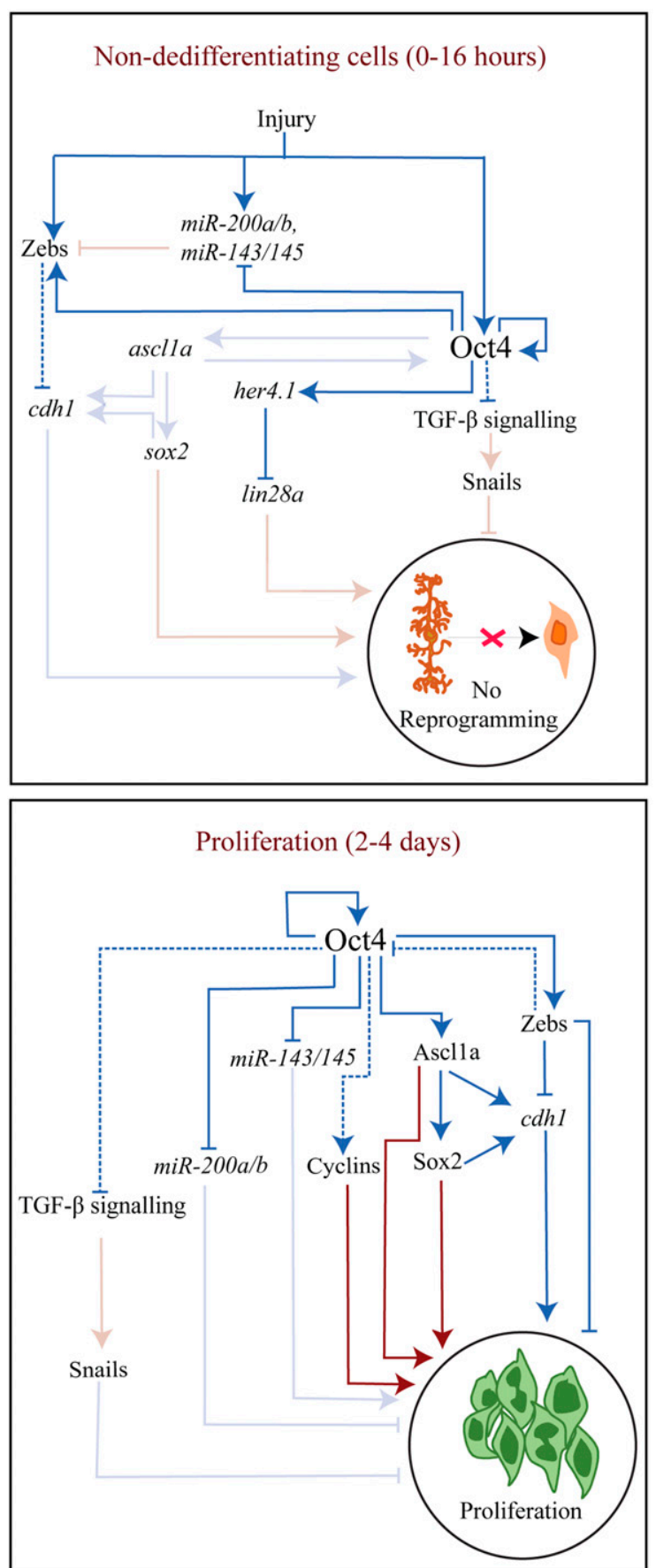

Dedifferentiating cells ( $0-2$ days)

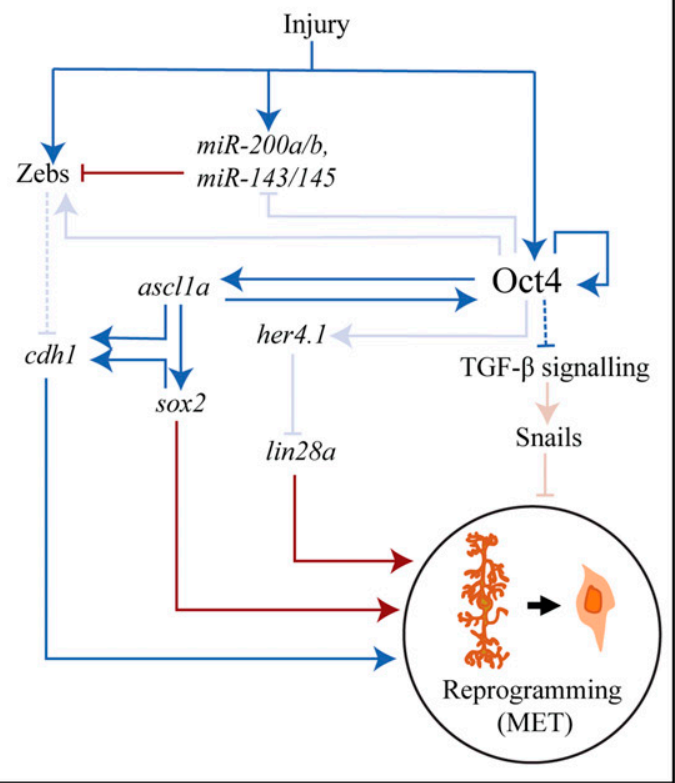

Redifferentiation (4-8 days)

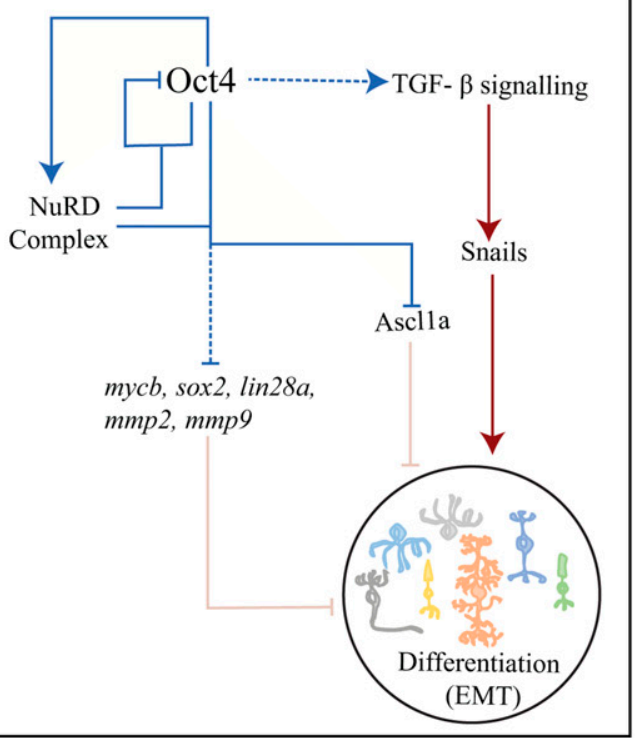

Faded connectors in respective colors: Nonfuntional in present situation

Activation: present study

Activation: present study, without direct proof

$\longrightarrow$ Inhibition: present study
$\ldots$-.----1 Inhibition: present study, without direct proof

$\rightarrow$ Activation: previuos studies

Inhibition: previuos studies

Figure 8. The gene regulatory network mediated through Oct4 regulatory axes in different phases of retina regeneration.

The model schematically describes gene regulatory mechanisms of various regeneration-associated factors discovered in this study along with already reported ones, at different stages of retina regeneration. 
per the manufacturer's instructions. The relative expression of mRNAs in control and injured retinae was deciphered using the $\Delta \Delta C t$ method and normalized to $\beta$-actin mRNA levels.

\section{Co-IP and ChIP assay}

Co-IP and ChIP assays were carried out in adult retina at different time points using 20 adult retinae after dark adaptation. Chromatin was isolated as described previously (Lindeman et al, 2009). After sonication, a part of chromatin was kept as input and remaining was distributed into two equal aliquots; one of them was pulled down with anti-Oct4, anti-Hdac1, anti-Ascl1a, or anti-Sox2 antibodies separately (described below) and other half was pulled down with rabbit IgG (Sigma-Aldrich) as negative control. Primers used for ChIP assays are described in Table S1.

For Co-IP, retinae were frozen at $-80^{\circ} \mathrm{C}$ in lysis buffer containing protease inhibitor cocktail and PMSF. Retinal lysate was prepared by thawing the sample in water followed by pipetting and vortexing. Lysate mixed with fresh lysis buffer containing protease inhibitor and PMSF was centrifuged at 9,425g for $10 \mathrm{~min}$ at $4^{\circ} \mathrm{C}$. Supernatant separated from cell debris was subjected to pull down with anti-Oct4 and anti-Hdac1 antibodies. Co-immunoprecipitated sample was lysed in Laemmli buffer and subjected to Western blotting as described below.

\section{Western blotting and quantification}

Western blotting was performed using six retinae per experimental sample, lysed in Laemmli buffer, size-fractioned in 12\% acrylamide gel at denaturing conditions, and transferred onto Immuno-Blot polyvinylidene fluoride (PVDF) membrane (cat. no. 162-0177; BioRad), followed by probing with specific primary antibodies and HRP-conjugated secondary antibodies for chemiluminescence assay using Clarity Western ECL (cat. no. 170-5061; Bio-Rad). Western blotting images were quantified with Imagel software and the values obtained were normalized to loading control (Gapdh) in each experimental setup. Fold change in protein expression of different samples was determined in comparison with the control injured retinae.

BrdU/EdU labeling, retina tissue preparation, immunofluorescence, ISH, FISH, and antibodies used

BrdU labeling was performed by a single intraperitoneal injection of $20 \mu \mathrm{l}$ of $\mathrm{BrdU}(20 \mathrm{mM}) 3 \mathrm{~h}$ before euthanasia and retina dissection unless mentioned specifically. EdU labeling was done by intravitreal injection of $10 \mathrm{mM}$ EdU solution as described earlier (Mitra et al, 2018, 2019). Fish were given a higher dose of tricaine methanesulphonate and eyes were dissected, lens removed, fixed in $4 \%$ paraformaldehyde, and sectioned as described previously (Fausett \& Goldman, 2006). The mRNA ISH was performed on retinal sections with fluorescein (FL) or digoxigenin (DIG)-labeled complementary RNA probes (FL/DIG RNA labeling kit; Roche Diagnostics) (Barthel \& Raymond, 2000). FISH was performed according to the manufacturer's directions (cat. no. T20917, B40955, and B40953; Thermo Fisher Scientific). Sense probes were used in every ISH separately as control, to assess the potential of background signal. Immunofluorescence microscopy protocols and antibodies were previously described (Ramachandran et al, 2010b; Wan et al, 2012; Mitra et al, 2019).

Other primary antibodies used for Western blotting and immunofluorescence were rabbit polyclonal antibody against Oct4 (AB3209; Merck), mouse monoclonal against Oct3/4 (sc5279; Santa Cruz Biotechnology), mouse polyclonal antibody against GFP (cat. no. ab38689; Abcam), rabbit polyclonal against GFP (cat. no. ab290; Abcam), rabbit polyclonal antibody against Sox2 (cat. no. ab59776; Abcam), rabbit polyclonal antibody against Hdac1 (cat. no. ab41407; Abcam), and rabbit polyclonal antibody against GAPDH (cat. no. SAB2701826; Sigma-Aldrich). Secondary antibodies used were goat anti rat/mouse/rabbit tagged to fluorescent dyes ranging from Alexa Fluor 488-647. The secondary antibody used in Western blotting analysis was HRP-conjugated anti-rabbit antibody.

\section{Fluorescence and confocal microscopy, cell counting, and statistical analysis}

After the completion of staining experiments, the slides were examined with a Nikon $\mathrm{Ni}$-E fluorescence microscope equipped with fluorescence optics and Nikon A1 confocal imaging system. The $\mathrm{PCNA}^{+}$and $\mathrm{BrdU}^{+}$cells were counted by observation of their fluorescence in retinal sections. $\mathrm{ISH}^{+}$cells were visualized through differential interference contrast in the same microscope and quantified. Observed data were analyzed for statistical significance by comparisons done using a two-tailed unpaired $t$ test to analyze data from all experiments. Error bars represent SD in all histograms.

\section{Fluorescence-based cell sorting}

RNA was isolated from FACS-purified MG and MG-derived progenitors at 4 dpi as previously described (Ramachandran et al, 2011, 2012b). Briefly, uninjured and injured retinae were isolated from 1016tuba1a:GFP transgenic fish. GFP+ MGPCs from 1016tuba1a:GFP retinae at $4 \mathrm{dpi}$ were isolated by treating retinae with hyaluronidase and trypsin and then sorted on a BD FACS Aria Fusion high-speed cell sorter. Approximately 30 injured retinae with 10 pokes per retina from 1016tuba1a:GFP fish yielded 70,000 $\mathrm{GFP}^{+}$and 150,000 $\mathrm{GFP}^{-}$cells.

\section{Supplementary Information}

Supplementary Information is available at https://doi.org/10.26508/lsa. 201900548.

\section{Acknowledgements}

P Sharma acknowledges postdoctoral fellowship support from the Wellcome Trust/DBT (Department of Biotechnology) India Alliance and Indian Institute of Science Education and Research (IISER), Mohali. S Gupta acknowledges her support from the Indian Council of Medical Research for Senior Research Fellowship. M Chaudhary, S Mitra, MA Khursheed, and B Chawla acknowledge their financial support from the IISER, Mohali. This work was supported by the Wellcome Trust/DBT India Alliance Intermediate Fellowship (IA/I/12/2/ 
500630) awarded to R Ramachandran. R Ramachandran also acknowledges research funding from Science Education and Research Board, Department of Science and Technology, India (EMR/2017/001816), DBT, India (BT/PR9407/ BRB/10/12612013), (BT/PR17912/MED/31/336/2016), and support from IISER Mohali.

\section{Author Contributions}

P Sharma: resources, data curation, formal analysis, validation, investigation, visualization, methodology, and writing-review and editing.

S Gupta: resources, methodology, and writing-review, and editing. M Choudhary: resources, methodology, and writing-review, and editing.

$S$ Mitra: resources.

B Chawla: resources.

MA Khursheed: resources and methodology.

R Ramachandran: conceptualization, resources, data curation, software, formal analysis, supervision, funding acquisition, validation, investigation, visualization, project administration, and writing-original draft, review, and editing.

\section{Conflict of Interest Statement}

The authors declare that they have no conflict of interest.

\section{References}

An J, Zheng Y, Dann CT (2017) Mesenchymal to epithelial transition mediated by $\mathrm{CDH} 1$ promotes spontaneous reprogramming of male germline stem cells to pluripotency. Stem Cell Reports 8: 446-459. doi:10.1016/ j.stemcr.2016.12.006

Barthel LK, Raymond PA (2000) In situ hybridization studies of retinal neurons. Methods Enzymol 316: 579-590. doi:10.1016/s0076-6879(00) 16751-5

Batlle E, Sancho E, Franci C, Dominguez D, Monfar M, Baulida J, Garcia De Herreros A (2000) The transcription factor snail is a repressor of Ecadherin gene expression in epithelial tumour cells. Nat Cell Biol 2: 84-89. doi:10.1038/35000034

Bernardos RL, Barthel LK, Meyers JR, Raymond PA (2007) Late-stage neuronal progenitors in the retina are radial Muller glia that function as retinal stem cells. J Neurosci 27: 7028-7040. doi:10.1523/jneurosci.162407.2007

Bologna-Molina R, Mosqueda-Taylor A, Molina-Frechero N, Mori-Estevez AD, Sanchez-Acuna G (2013) Comparison of the value of PCNA and Ki-67 as markers of cell proliferation in ameloblastic tumors. Med Oral Patol Oral Cir Bucal 18: e174-179. doi:10.4317/medoral.18573

Brzezinski JA 4th, Kim EJ, Johnson JE, Reh TA (2011) Ascl1 expression defines a subpopulation of lineage-restricted progenitors in the mammalian retina. Development 138: 3519-3531. doi:10.1242/dev.064006

Buganim Y, Faddah DA, Jaenisch R (2013) Mechanisms and models of somatic cell reprogramming. Nat Rev Genet 14: 427-439. doi:10.1038/nrg3473

Chen F, Zhang G, Yu L, Feng Y, Li X, Zhang Z, Wang Y, Sun D, Pradhan S (2016) High-efficiency generation of induced pluripotent mesenchymal stem cells from human dermal fibroblasts using recombinant proteins. Stem Cell Res Ther 7: 99. doi:10.1186/s13287-016-0358-4

Chua HL, Bhat-Nakshatri P, Clare SE, Morimiya A, Badve S, Nakshatri H (2007) NF-kappaB represses E-cadherin expression and enhances epithelial to mesenchymal transition of mammary epithelial cells: Potential involvement of ZEB-1 and ZEB-2. Oncogene 26: 711-724. doi:10.1038/ sj.onc.1209808

Close IL, Gumuscu B, Reh TA (2005) Retinal neurons regulate proliferation of postnatal progenitors and Muller glia in the rat retina via TGF beta signaling. Development 132: 3015-3026. doi:10.1242/dev.01882

Dong LL, Liu L, Ma CH, Li JS, Du C, Xu S, Han LH, Li L, Wang XW (2012) E-cadherin promotes proliferation of human ovarian cancer cells in vitro via activating MEK/ERK pathway. Acta Pharmacol Sin 33: 817-822. doi:10.1038/aps.2012.30

Esteban MA, Bao X, Zhuang O, Zhou T, Qin B, Pei D (2012) The mesenchymalto-epithelial transition in somatic cell reprogramming. Curr Opin Genet Dev 22: 423-428. doi:10.1016/j.gde.2012.09.004

Fausett BV, Goldman D (2006) A role for alpha1 tubulin-expressing Muller glia in regeneration of the injured zebrafish retina. J Neurosci 26: 6303-6313. doi:10.1523/jneurosci.0332-06.2006

Fausett BV, Gumerson JD, Goldman D (2008) The proneural basic helix-loophelix gene ascl1a is required for retina regeneration. J Neurosci 28: 1109-1117. doi:10.1523/jneurosci.4853-07.2008

Flynt AS, Thatcher EJ, Burkewitz K, Li N, Liu Y, Patton JG (2009) miR-8 microRNAs regulate the response to osmotic stress in zebrafish embryos. J Cell Biol 185: 115-127. doi:10.1083/jcb.200807026

Forte E, Chimenti I, Rosa P, Angelini F, Pagano F, Calogero A, Giacomello A, Messina E (2017) EMT/MET at the crossroad of stemness, regeneration and oncogenesis: The ying-yang equilibrium recapitulated in cell spheroids. Cancers (Basel) 9: E98. doi:10.3390/cancers9080098

Galvan JA, Zlobec I, Wartenberg M, Lugli A, Gloor B, Perren A, Karamitopoulou E (2015) Expression of E-cadherin repressors SNAIL, ZEB1 and ZEB2 by tumour and stromal cells influences tumour-budding phenotype and suggests heterogeneity of stromal cells in pancreatic cancer. Br J Cancer 112: 1944-1950. doi:10.1038/bjc.2015.177

Gemberling M, Bailey TJ, Hyde DR, Poss KD (2013) The zebrafish as a model for complex tissue regeneration. Trends Genet 29: 611-620. doi:10.1016/ j.tig.2013.07.003

Gheldof A, Hulpiau P, van Roy F, De Craene B, Berx G (2012) Evolutionary functional analysis and molecular regulation of the ZEB transcription factors. Cell Mol Life Sci 69: 2527-2541. doi:10.1007/s00018-012-0935-3

Goldman D (2014) Muller glial cell reprogramming and retina regeneration. Nat Rev Neurosci 15: 431-442. doi:10.1038/nrn3723

Gorsuch RA, Hyde DR (2014) Regulation of Muller glial dependent neuronal regeneration in the damaged adult zebrafish retina. Exp Eye Res 123: 131-140. doi:10.1016/j.exer.2013.07.012

Gorsuch RA, Lahne M, Yarka CE, Petravick ME, Li J, Hyde DR (2017) Sox2 regulates Muller glia reprogramming and proliferation in the regenerating zebrafish retina via Lin28 and Ascl1a. Exp Eye Res 161: 174-192. doi:10.1016/j.exer.2017.05.012

Hu G, Wade PA (2012) NuRD and pluripotency: A complex balancing act. Cell Stem Cell 10: 497-503. doi:10.1016/j.stem.2012.04.011

Huang S, Guo W, Tang Y, Ren D, Zou X, Peng X (2012) miR-143 and miR-145 inhibit stem cell characteristics of PC-3 prostate cancer cells. Oncol Rep 28: 1831-1837. doi:10.3892/or.2012.2015

Hugo HJ, Pereira L, Suryadinata R, Drabsch Y, Gonda TJ, Gunasinghe NP, Pinto C, Soo ET, van Denderen BJ, Hill P, et al (2013) Direct repression of MYB by ZEB1 suppresses proliferation and epithelial gene expression during epithelial-to-mesenchymal transition of breast cancer cells. Breast Cancer Res 15: R113. doi:10.1186/bcr3580

Jorstad NL, Wilken MS, Grimes WN, Wohl SG, VandenBosch LS, Yoshimatsu T, Wong RO, Rieke F, Reh TA (2017) Stimulation of functional neuronal regeneration from Muller glia in adult mice. Nature 548: 103-107. doi:10.1038/nature23283

Kaur S, Gupta S, Chaudhary M, Khursheed MA, Mitra S, Kurup AJ, Ramachandran R (2018) let-7 MicroRNA-mediated regulation of Shh 
signaling and the gene regulatory network is essential for retina regeneration. Cell Rep 23: 1409-1423. doi:10.1016/j.celrep.2018.04.002

Kemler I, Bucher E, Seipel K, Muller-Immergluck MM, Schaffner W (1991) Promoters with the octamer DNA motif (ATGCAAAT) can be ubiquitous or cell type-specific depending on binding affinity of the octamer site and Oct-factor concentration. Nucleic Acids Res 19: 237-242. doi:10.1093/nar/19.2.237

Kimmel RA, Meyer D (2010) Molecular regulation of pancreas development in zebrafish. Methods Cell Biol 100: 261-280. doi:10.1016/b978-0-12384892-5.00010-4

Lagendijk AK, Goumans MJ, Burkhard SB, Bakkers J (2011) MicroRNA-23 restricts cardiac valve formation by inhibiting Has2 and extracellular hyaluronic acid production. Circ Res 109: 649-657. doi:10.1161/ circresaha.111.247635

Lengner CJ, Camargo FD, Hochedlinger K, Welstead GG, Zaidi S, Gokhale S, Scholer HR, Tomilin A, Jaenisch R (2007) Oct4 expression is not required for mouse somatic stem cell self-renewal. Cell Stem Cell 1: 403-415. doi:10.1016/j.stem.2007.07.020

Lenkowski JR, Qin Z, Sifuentes CJ, Thummel R, Soto CM, Moens CB, Raymond PA (2013) Retinal regeneration in adult zebrafish requires regulation of TGFbeta signaling. Glia 61: 1687-1697. doi:10.1002/glia.22549

Li R, Liang J, Ni S, Zhou T, Qing X, Li H, He W, Chen J, Li F, Zhuang Q, et al (2010) A mesenchymal-to-epithelial transition initiates and is required for the nuclear reprogramming of mouse fibroblasts. Cell Stem Cell 7: 51-63. doi:10.1016/j.stem.2010.04.014

Lindeman LC, Vogt-Kielland LT, Alestrom P, Collas P (2009) Fish'n ChIPs: Chromatin immunoprecipitation in the zebrafish embryo. Methods Mol Biol 567: 75-86. doi:10.1007/978-1-60327-414-2_5

Liu X, Sun H, Qi J, Wang L, He S, Liu J, Feng C, Chen C, Li W, Guo Y, et al (2013) Sequential introduction of reprogramming factors reveals a timesensitive requirement for individual factors and a sequential EMTMET mechanism for optimal reprogramming. Nat Cell Biol 15: 829-838. doi:10.1038/ncb2765

Lowry WE, Richter L, Yachechko R, Pyle AD, Tchieu J, Sridharan R, Clark AT, Plath K (2008) Generation of human induced pluripotent stem cells from dermal fibroblasts. Proc Natl Acad Sci U S A 105: 2883-2888. doi:10.1073/pnas.0711983105

Mandyam CD, Harburg GC, Eisch AJ (2007) Determination of key aspects of precursor cell proliferation, cell cycle length and kinetics in the adult mouse subgranular zone. Neuroscience 146: 108-122. doi:10.1016/ j.neuroscience.2006.12.064

Mistri TK, Devasia AG, Chu LT, Ng WP, Halbritter F, Colby D, Martynoga B, Tomlinson SR, Chambers I, Robson P, et al (2015) Selective influence of Sox2 on POU transcription factor binding in embryonic and neural stem cells. EMBO Rep 16: 1177-1191. doi:10.15252/embr.201540467

Mitra S, Sharma P, Kaur S, Khursheed MA, Gupta S, Ahuja R, Kurup AJ, Chaudhary M, Ramachandran R (2018) Histone deacetylase-mediated muller glia reprogramming through Her4.1-Lin28a axis is essential for retina regeneration in zebrafish. iscience 7: 68-84. doi:10.1016/ j.isci.2018.08.008

Mitra S, Sharma P, Kaur S, Khursheed MA, Gupta S, Chaudhary M, Kurup AJ, Ramachandran R (2019) Dual regulation of lin28a by Myc is necessary during zebrafish retina regeneration. J Cell Biol 218: 489-507. doi:10.1083/jcb.201802113

Morrison GM, Brickman JM (2006) Conserved roles for Oct4 homologues in maintaining multipotency during early vertebrate development. Development 133: 2011-2022. doi:10.1242/dev.02362

Nagamatsu G, Saito S, Kosaka T, Takubo K, Kinoshita T, Oya M, Horimoto K, Suda T (2012) Optimal ratio of transcription factors for somatic cell reprogramming. J Biol Chem 287: 36273-36282. doi:10.1074/ jbc.m112.380683

Nichols J, Zevnik B, Anastassiadis K, Niwa H, Klewe-Nebenius D, Chambers I, Scholer H, Smith A (1998) Formation of pluripotent stem cells in the mammalian embryo depends on the POU transcription factor Oct4. Cell 95: 379-391. doi:10.1016/s0092-8674(00)81769-9

Oblander SA, Ensslen-Craig SE, Longo FM, Brady-Kalnay SM (2007) E-cadherin promotes retinal ganglion cell neurite outgrowth in a protein tyrosine phosphatase-mu-dependent manner. Mol Cell Neurosci 34: 481-492. doi:10.1016/j.mcn.2006.12.002

Papp B, Plath K (2013) Epigenetics of reprogramming to induced pluripotency. Cell 152: 1324-1343. doi:10.1016/j.cell.2013.02.043

Park SM, Gaur AB, Lengyel E, Peter ME (2008) The miR-200 family determines the epithelial phenotype of cancer cells by targeting the E-cadherin repressors ZEB1 and ZEB2. Genes Dev 22: 894-907. doi:10.1101/ gad.1640608

Park SY, Shin JH, Kee SH (2017) E-cadherin expression increases cell proliferation by regulating energy metabolism through nuclear factor-kappaB in AGS cells. Cancer Sci 108: 1769-1777. doi:10.1111/ cas.13321

Peinado H, Olmeda D, Cano A (2007) Snail, Zeb and bHLH factors in tumour progression: An alliance against the epithelial phenotype? Nat Rev Cancer 7: 415-428. doi:10.1038/nrc2131

Polo JM, Anderssen E, Walsh RM, Schwarz BA, Nefzger CM, Lim SM, Borkent M, Apostolou E, Alaei S, Cloutier J, et al (2012) A molecular roadmap of reprogramming somatic cells into iPS cells. Cell 151: 1617-1632. doi:10.1016/j.cell.2012.11.039

Radzisheuskaya A, Chia Gle B, dos Santos RL, Theunissen TW, Castro LF, Nichols J, Silva JC (2013) A defined Oct4 level governs cell state transitions of pluripotency entry and differentiation into all embryonic lineages. Nat Cell Biol 15: 579-590. doi:10.1038/ncb2742

Radzisheuskaya A, Silva JC (2014) Do all roads lead to Oct4? The emerging concepts of induced pluripotency. Trends Cell Biol 24: 275-284. doi:10.1016/j.tcb.2013.11.010

Ramachandran R, Fausett BV, Goldman D (2010a) Ascl1a regulates Muller glia dedifferentiation and retinal regeneration through a Lin-28dependent, let-7 microRNA signalling pathway. Nat Cell Biol 12: 1101-1107. doi:10.1038/ncb2115

Ramachandran R, Reifler A, Parent JM, Goldman D (2010b) Conditional gene expression and lineage tracing of tuba1a expressing cells during zebrafish development and retina regeneration. J Comp Neurol 518: 4196-4212. doi:10.1002/cne.22448

Ramachandran R, Reifler A, Wan J, Goldman D (2012a) Application of Cre-loxP recombination for lineage tracing of adult zebrafish retinal stem cells. Methods Mol Biol 884: 129-140. doi:10.1007/978-1-61779-848-1_8

Ramachandran R, Zhao XF, Goldman D (2011) Ascl1a/Dkk/beta-catenin signaling pathway is necessary and glycogen synthase kinase-3beta inhibition is sufficient for zebrafish retina regeneration. Proc Natl Acad Sci U S A 108: 15858-15863. doi:10.1073/pnas.1107220108

Ramachandran R, Zhao XF, Goldman D (2012b) Insm1a-mediated gene repression is essential for the formation and differentiation of Muller glia-derived progenitors in the injured retina. Nat Cell Biol 14: 1013-1023. doi:10.1038/ncb2586

Redmer T, Diecke S, Grigoryan T, Quiroga-Negreira A, Birchmeier W, Besser D (2011) E-cadherin is crucial for embryonic stem cell pluripotency and can replace OCT4 during somatic cell reprogramming. EMBO Rep 12: 720-726. doi:10.1038/embor.2011.88

Reyes-Aguirre LI, Lamas M (2016) Oct4 methylation-mediated silencing as an epigenetic barrier preventing muller glia dedifferentiation in a murine model of retinal injury. Front Neurosci 10: 523. doi:10.3389/ fnins.2016.00523

Sanchez-Tillo E, Lazaro A, Torrent R, Cuatrecasas M, Vaquero EC, Castells A, Engel P, Postigo A (2010) ZEB1 represses E-cadherin and induces an EMT by recruiting the SWI/SNF chromatin-remodeling protein BRG1. Oncogene 29: 3490-3500. doi:10.1038/onc.2010.102 
Schulte J, Weidig M, Balzer P, Richter P, Franz M, Junker K, Gajda M, Friedrich K, Wunderlich H, Ostman A, et al (2012) Expression of the E-cadherin repressors Snail, Slug and Zeb1 in urothelial carcinoma of the urinary bladder: Relation to stromal fibroblast activation and invasive behaviour of carcinoma cells. Histochem Cell Biol 138: 847-860. doi:10.1007/s00418-012-0998-0

Shen L, Qin K, Wang D, Zhang Y, Bai N, Yang S, Luo Y, Xiang R, Tan X (2014) Overexpression of Oct 4 suppresses the metastatic potential of breast cancer cells via Rnd1 downregulation. Biochim Biophys Acta 1842: 2087-2095. doi:10.1016/j.bbadis.2014.07.015

Shu X, Pei D (2014) The function and regulation of mesenchymal-to-epithelial transition in somatic cell reprogramming. Curr Opin Genet Dev 28: 32-37. doi:10.1016/j.gde.2014.08.005

Soufi A, Donahue G, Zaret KS (2012) Facilitators and impediments of the pluripotency reprogramming factors' initial engagement with the genome. Cell 151: 994-1004. doi:10.1016/j.cell.2012.09.045

Tan F, Qian C, Tang K, Abd-Allah SM, Jing N (2015) Inhibition of transforming growth factor beta (TGF-beta) signaling can substitute for Oct4 protein in reprogramming and maintain pluripotency. J Biol Chem 290: 4500-4511. doi:10.1074/jbc.m114.609016

Todd L, Palazzo I, Squires N, Mendonca N, Fischer AJ (2017) BMP- and TGFbetasignaling regulate the formation of Muller glia-derived progenitor cells in the avian retina. Glia 65: 1640-1655. doi:10.1002/glia.23185

van den Berg DL, Snoek T, Mullin NP, Yates A, Bezstarosti K, Demmers J, Chambers I, Poot RA (2010) An Oct4-centered protein interaction network in embryonic stem cells. Cell Stem Cell 6: 369-381. doi:10.1016/j.stem.2010.02.014

van Roy F, Berx G (2008) The cell-cell adhesion molecule E-cadherin. Cell Mol Life Sci 65: 3756-3788. doi:10.1007/s00018-008-8281-1

Vannier C, Mock K, Brabletz T, Driever W (2013) Zeb1 regulates E-cadherin and Epcam (epithelial cell adhesion molecule) expression to control cell behavior in early zebrafish development. I Biol Chem 288: 18643-18659. doi:10.1074/jbc.m113.467787

Wan J, Goldman D (2016) Retina regeneration in zebrafish. Curr Opin Genet Dev 40: 41-47. doi:10.1016/j.gde.2016.05.009
Wan J, Ramachandran R, Goldman D (2012) HB-EGF is necessary and sufficient for Muller glia dedifferentiation and retina regeneration. Dev Cell 22: 334-347. doi:10.1016/j.devcel.2011.11.020

Wang G, Guo X, Hong W, Liu Q, Wei T, Lu C, Gao L, Ye D, Zhou Y, Chen J, et al (2013) Critical regulation of miR-200/ZEB2 pathway in Oct4/Sox2induced mesenchymal-to-epithelial transition and induced pluripotent stem cell generation. Proc Natl Acad Sci U S A 110: 2858-2863. doi:10.1073/pnas.1212769110

Wellner U, Schubert J, Burk UC, Schmalhofer O, Zhu F, Sonntag A, Waldvogel B, Vannier C, Darling D, zur Hausen A, et al (2009) The EMT-activator ZEB1 promotes tumorigenicity by repressing stemness-inhibiting microRNAs. Nat Cell Biol 11: 1487-1495. doi:10.1038/ncb1998

Wells A, Yates C, Shepard CR (2008) E-cadherin as an indicator of mesenchymal to epithelial reverting transitions during the metastatic seeding of disseminated carcinomas. Clin Exp Metastasis 25: 621-628. doi:10.1007/s10585-008-9167-1

Wilken MS, Reh TA (2016) Retinal regeneration in birds and mice. Curr Opin Genet Dev 40: 57-64. doi:10.1016/j.gde.2016.05.028

Xiong F, Ma W, Hiscock TW, Mosaliganti KR, Tentner AR, Brakke KA, Rannou N, Gelas A, Souhait L, Swinburne IA, et al (2014) Interplay of cell shape and division orientation promotes robust morphogenesis of developing epithelia. Cell 159: 415-427. doi:10.1016/j.cell.2014.09.007

Zhang P, Sun Y, Ma L (2015) ZEB1: At the crossroads of epithelialmesenchymal transition, metastasis and therapy resistance. Cell Cycle 14: 481-487. doi:10.1080/15384101.2015.1006048

Zhao XF, Wan J, Powell C, Ramachandran R, Myers MG Jr, Goldman D (2014) Leptin and IL-6 family cytokines synergize to stimulate Muller glia reprogramming and retina regeneration. Cell Rep 9: 272-284. doi:10.1016/j.celrep.2014.08.047

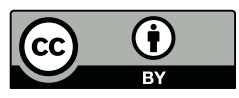

License: This article is available under a Creative Commons License (Attribution 4.0 International, as described at https://creativecommons.org/ licenses/by/4.0/). 